\title{
Empirical relationships between summertime oceanic heat anomalies in the Nordic seas and large-scale atmospheric circulation in the following winter
}

\author{
Pawel Schlichtholz ${ }^{1}$
}

Received: 31 March 2015 / Accepted: 29 November 2015 / Published online: 4 January 2016

(c) The Author(s) 2015. This article is published with open access at Springerlink.com

\begin{abstract}
A lagged regression analysis between an index of observed summertime Atlantic water temperature (AWT) variability at the entrance to the Barents Sea in the period 1982-2005 and year-round atmospheric (NCEP/NCAR) reanalysis data is used to show that subsurface oceanic heat anomalies in high latitudes are significant precursors of wintertime atmospheric variability in middle latitudes. In particular, positive AWT anomalies precede predominantly westerly wind anomalies in high latitudes and easterly wind anomalies in middle latitudes. The mid-latitude wind anomalies, while being generally equivalent barotropic in the upper troposphere, have a strong low-level baroclinic contribution over Eurasia. The near-surface easterly wind anomalies in this area are locally deflected southward, maintaining cold spots near orography. The summertime oceanic anomalies explain about $40 \%$ of the variance in the surface air temperature averaged over Eurasia from $35^{\circ}$ to $45^{\circ} \mathrm{N}$ and about $50 \%$ of the variance in surface winds over the Far East Asia in the following winter. We suggest that the remote connections arise from reorganization of the mid-latitude storm tracks. The AWT anomalies explain about $60 \%$ of the variance in the upper-tropospheric storm track activity averaged over the Pacific and Eurasia from $35^{\circ}$ to $55^{\circ} \mathrm{N}$ and in the lower-tropospheric poleward synoptic eddy heat flux over western Eurasia. Finally, we show that the AWT-associated wintertime atmospheric anomalies appear in quadrature with the concurrent anomalies associated with the North Atlantic Oscillation. These findings
\end{abstract}

Pawel Schlichtholz

schlicht@iopan.gda.pl

1 Institute of Oceanology, Polish Academy of Sciences, Powstancow Warszawy 55, 81-712 Sopot, Poland suggest that oceanic heat anomalies in high latitudes may be a useful predictor of atmospheric variability.

Keywords Interannual climate variability - Oceanic heat anomalies $\cdot$ Nordic seas $\cdot$ Atmospheric circulation $\cdot$ Storm tracks $\cdot$ Teleconnections

\section{Introduction}

There is a growing evidence that Arctic sea ice anomalies influence mid-latitude weather and climate through coupled changes in the polar jet stream, planetary waves and storm tracks (e.g., Cohen et al. 2014; Vihma 2014). In particular, autumn-to-winter atmospheric circulation, temperature and snowfalls in northern continents seem to 'remember' Arctic sea ice extent during the previous summer (Francis et al. 2009; Honda et al. 2009; Overland and Wang 2010; Jaiser et al. 2012). This link is, however, not robust (Hopsch et al. 2012; Screen and Simmonds 2013). A relation of anomalous winter weather extremes over Eurasia to the concurrent anomalies of Arctic sea ice extent is more significant (Tang et al. 2013). The wintertime atmospheric conditions over Eurasia are particularly sensitive to disturbances of sea ice cover in the Barents Sea (Petoukhov and Semenov 2010; Inoue et al. 2012; Kim et al. 2014; Mori et al. 2014). The latter is a shelf sea on the eastern side of the Nordic (Greenland-Iceland-Norwegian and Barents) seas (Fig. 1a).

A regional coupled sea ice-ocean model indicates that the annual mean sea ice extent in the Barents Sea is significantly linked to anomalous volume transport of Atlantic water through the Barents Sea opening (BSO) 1-year earlier (Årthun et al. 2012). Observations show that $50 \%$ of variability in the annual mean Barents Sea ice cover, which is dominated by wintertime ice anomalies, can be 

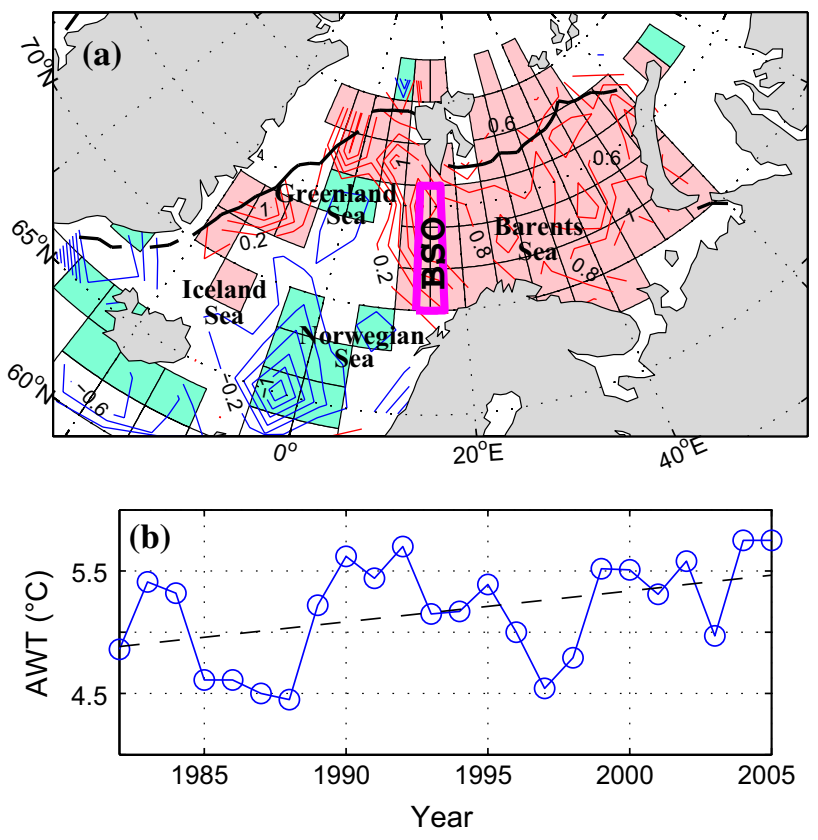

Fig. 1 a Difference in the composite mean of the summer (JJAS) average temperature in the 50-150 m layer in the Nordic seas and b the time series of Atlantic water temperature in the Barents Sea opening (circles) and its trend (dashed line). In a, the difference is between seven 'BSO warm summers' and seven 'BSO cold summers' corresponding to, respectively, the highest and lowest values of the AWT index (detrended time series from $\mathbf{b}$ ). The composite means are calculated from data in $2^{\circ}$ latitude by $5^{\circ}$ longitude boxes. The difference is plotted only for the boxes in which the composite means are based on data from at least 10 hydrographic stations each. The red and blue contours represent positive and negative differences, respectively. The contour interval $(\mathrm{CI})$ is $0.2 \mathrm{~K}$. The zero contour is omitted. Pink and aquamarine shading denote positive and negative differences statistically significant at the $99 \%$ confidence level, respectively. The thick black line shows the climatological summer ice edge (15\% sea ice concentration contour)

predicted up to 2 years in advance from the ocean heat transport through the BSO (Onarheim et al. 2015). The wintertime variability of sea ice cover in the Barents Sea is not only influenced by changes in the Atlantic water transport, but also by anomalies of Atlantic water temperature (AWT). The latter are either advected from the North Atlantic (Nakanowatari et al. 2014) or driven by local airsea interactions occurring in the Nordic seas region during the preceding winter-to-spring season (Schlichtholz and Houssais 2011). Whatever their origin, the subsurface ocean temperature anomalies, which in summer are insulated from interactions with the atmosphere by a shallow seasonal pycnocline, are entrained into the deepening ocean surface mixed layer during the cooling season and subsequently affect sea ice formation. Using the NCEP Climate Forecast System Reanalysis (CFSR), Nakanowatari et al. (2014) show that $35 \%$ of the sea ice concentration variability in the Barents Sea in November-December can be skillfully predicted by 1-year earlier upstream AWT anomalies.

A statistical analysis of oceanic observations in the period 1982-2006 indicates that more than $70 \%$ of the interannual variance of the total wintertime sea ice area in the Nordic seas region can be explained by AWT anomalies at the entrance to the Barents Sea in the preceding summer (Schlichtholz 2011). When brought to the surface, oceanic heat anomalies influence not only the sea ice cover in the Nordic seas but also the local atmospheric conditions in this region (Schlichtholz 2014). The sea ice and atmospheric anomalies may persist in winter because of a feedback between oceanically-driven wind anomalies and wind-driven AWT anomalies (Schlichtholz 2013).

A question is whether remote effects of sea ice anomalies are modulated by interannual variability in oceanic forcing. The statistical analysis carried out by Nakanowatari et al. (2014) suggests that the answer to this question is positive. In particular, these authors show that surface air temperature anomalies regressed onto the leading mode of the canonical component time series of the NovemberDecember sea ice concentration in the Barents Sea associated with the 1-year earlier subsurface ocean temperatures in the Nordic seas exhibit a 'warm Arctic-cold Eurasia' pattern when the ocean temperatures are anomalously high and the sea ice extent is anomalously low (Nakanowatari et al. 2014, their Fig. 20a). Here we provide a further support for the scenario in which subsurface oceanic heat anomalies in high latitudes are significant precursors of wintertime variability in middle latitudes. To this end, we regress seasonal mean atmospheric fields in the extratropical Northern Hemesphere from the National Centers for Environmental Prediction/National Center for Atmospheric Research (NCEP/NCAR) reanalysis (Kalnay et al. 1996) onto an index of summertime AWT anomalies in the BSO area (magenta box in Fig. 1a).

The study is organized as follows. Data and methods are described in Sect. 2. Main results are presented in Sect. 3. As we relate the large-scale atmospheric variability to oceanic anomalies in a small area (BSO), it is important to emphasize that these anomalies represent coherent oceanic variability in the entire Nordic seas region rather than random local fluctuations. This is done in Sect. 3.1 using a composite analysis of observed summertime temperature anomalies in the Nordic seas. Then, in Sect. 3.2, statistical relations of the summer AWT index to the large-scale atmospheric variability in the following winter are analyzed. The focuss is on air temperature and winds in the troposphere. Areas with significant remote anomalies are found in Central Eurasia, Far East and East Pacific/Alaska. Next, in Sect. 3.3, it is suggested, based on the analysis of synoptic variability, that these teleconnections are related to reorganization of storm tracks. A discussion follows in 
Sect. 4. An important finding, discussed in Sect. 4.1, is that the AWT-related circulation changes and the concurrent changes related to the most prominent mode of wintertime extratropical atmospheric variability in the Northern Hemisphere, the North Atlantic Oscillation (NAO), are uncorrelated during the analyzed period. This increases a potential for seasonal prediction based on summer AWT anomalies. A short comparison with some studies of atmospheric links to anomalous sea ice cover in the Barents Sea is presented in Sect. 4.2. It is then recognized, based on the analysis of sea surface temperature (SST) in the North Atlantic (Sect. 4.3) and Pacific (Sect. 4.4), that some of the AWT-related atmospheric anomalies may represent or include an atmospheric response to oceanic forcing in other regions than the Nordic seas. Finally, conclusions are given in Sect. 5.

\section{Data and methods}

\subsection{Ocanic data and composite analysis}

Oceanic heat variability is represented by the summer (JJAS) time series of AWT constructed by Schlichtholz and Houssais (2011) for the period 1982-2005 (Fig. 1b, circles) using temperature data from the International Council for the Exploration of the Sea (ICES) Oceanographic Database (International Council for the Exploration of the Sea 2006) and from the the World Ocean Database 2005 (WOD05) compiled by the US National Oceanographic Data Center (Boyer et al. 2006). The temperature data were averaged over the Atlantic water core (100-300 m) in the BSO area $\left(13-17^{\circ} \mathrm{E}, 70-76^{\circ} \mathrm{N}\right.$; magenta box in Fig. 1a). The AWT index used throughout this study is defined as the time series of the linearly detrended anomalies of AWT from Fig. $1 \mathrm{~b}$ divided by their standard deviation (about $0.4 \mathrm{~K}$ ).

Temperature data from the ICES and WOD05 databases are also used in a composite analysis performed to compare subsurface ocean temperature variability in the BSO area and other areas of the Nordic seas, for most of which construction of a reliable time series is hindered by insufficient number of hydrographic stations. To this end, first seven 'BSO warm summers' (1983, 1984, 1990, 1991, 1992, 2004, and 2005) and seven 'BSO cold summers' (1985, 1986, 1987, 1988, 1997, 1998, and 2003) corresponding to, respectively, the highest and lowest values of the AWT index are selected. Then, composite means for the summer average temperature in the $50-150 \mathrm{~m}$ layer during these epochs are constructed using data from stations occupied not earlier than the beginning of June and not later than the end of September. The composite means are calculated for $2^{\circ}$ latitude by $5^{\circ}$ longitude boxes using only temperature profiles deeper than $150 \mathrm{~m}$. The upper
(50 m) depth limit excludes the surface mixed layer from the analysis. The lower $(150 \mathrm{~m})$ depth limit allows for extension of the analysis to shallow parts of the Barents Sea. Repeated stations or the same stations in both datasets are taken only once. For each box, stations with anomalies of average temperature in the 50-150 m layer exceeding 5 standard deviations are disregarded. Finally, differences in the composite means ('BSO warm summers' minus 'BSO cold summers') are calculated for the boxes for which data from at least 10 stations contribute to the composite in each of the two epochs. Typically, a hundred or more stations contribute in the open water areas of the Barents and Greenland Seas (see the thick black contour in Fig. 1a for the summer mean ice edge location based on the sea ice concentration data used in the NCEP/NCAR reanalysis). For instance, more than 100 stations are found in both epochs in 47 out of 80 boxes in the whole area between $70^{\circ}$ and $80^{\circ} \mathrm{N}$ from Greenland to Novaya Zemlya. The significance of the composite mean difference is tested using a $t$-statistic with the number of degrees of freedom determined from the temperature variances in both epochs (von Storch and Zwiers 1999, p. 113).

\subsection{Atmospheric data}

Seasonal (4-month)-mean atmospheric fields are constructed using monthly or daily mean data at constant pressure levels from the NCEP/NCAR reanalysis on a $2.5^{\circ}$ latitude $\times 2.5^{\circ}$ longitude grid (Kalnay et al. 1996). The monthly fields include the geopotential height $Z$, meridional ( $v$, positive northward) and zonal ( $u$, positive eastward) components of the wind velocity $\mathbf{u}$, temperature $T$ and potential temperature $\theta$. In addition, the net total surface heat flux (positive upward) from the NCEP/NCAR reanalysis on the T62 $\left(\sim 2^{\circ}\right.$ long $\times \sim 2^{\circ}$ lat $)$ grid is used.

The geostrophic wind $\mathbf{u}_{g}$ at selected pressure levels and an estimate of the average temperature $T_{\Delta Z}$ between an upper level $p_{u}$ and a lower level $p_{l}$ are calculated as follows:

$\mathbf{u}_{g}=\frac{g}{f} \mathbf{k} \times \nabla_{h} Z \quad$ and $\quad T_{\Delta Z}=\frac{g}{R_{a}}\left[Z\left(p_{u}\right)-Z\left(p_{l}\right)\right] \ln \left(\frac{p_{u}}{p_{l}}\right)$,

where $g, f, \mathbf{k}, \nabla_{h}$, and $R_{a}$ are acceleration due to gravity, the Coriolis parameter, a vertical unit vector, the horizontal gradient operator, and the gas constant of air, respectively. The potential temperature is used to calculate the buoyancy frequency $N=[(g / \theta)(\partial \theta / \partial z)]^{1 / 2}$ in log-pressure coordinates $z=-H \ln \left(p / p_{s}\right)$, where $p$ is pressure, $p_{s}$ is pressure at the surface (assumed equal to $1000 \mathrm{hPa}$ ), and $H$ is a scale height (assumed equal to $8.5 \mathrm{~km}$ ). The buoyancy frequency and wind velocity are used to calculate the Eady baroclinic 
Table 1 Correlation $(r)$ of the summer (JJAS) AWT index with the area-averaged air temperature $(T)$ at $1000 \mathrm{hPa}$, meridional wind $(v)$ at $1000 \mathrm{hPa}$, zonal wind $(u)$ at $300 \mathrm{hPa}$, synoptic storm track activity $\left({\overline{Z^{\prime} Z^{\prime}}}^{1 / 2}\right)$ at $250 \mathrm{hPa}$, and poleward synoptic eddy heat flux $\overline{\left(\overline{v^{\prime} T^{\prime}}\right)}$ at
$925 \mathrm{hPa}$ in the following winter (DJFM). The region over which $T, v$, $u, \overline{Z^{\prime} Z^{\prime}} 1 / 2$ and $\overline{v^{\prime} T^{\prime}}$ are averaged and the number of Figure in which this region is marked are specified in the third and fourth column, respectively

\begin{tabular}{llllrr}
\hline Variable & Level $(\mathrm{hPa})$ & Area & Figures & $r$ & $s_{e}(\%)$ \\
\hline$T$ & 1000 & $35^{\circ}-45^{\circ} \mathrm{N}, 30^{\circ} \mathrm{W}-130^{\circ} \mathrm{E}$ & Fig. 2a & -0.63 & 99.3 \\
$v$ & 1000 & $35^{\circ}-45^{\circ} \mathrm{N}, 125^{\circ}-135^{\circ} \mathrm{E}$ & Fig. 5 & -0.72 & 99.9 \\
$u$ & 300 & $60^{\circ}-65^{\circ} \mathrm{N}, 135^{\circ}-155^{\circ} \mathrm{W}$ & Fig. 3b & 0.61 & 99.9 \\
$\overline{Z^{\prime} Z^{\prime}}$ & 250 & $35^{\circ}-55^{\circ} \mathrm{N}, 0^{\circ}-250^{\circ} \mathrm{E}$ & Fig. 8a & -0.77 & 18.5 \\
$\overline{v^{\prime} T^{\prime}}$ & 925 & $45^{\circ}-60^{\circ} \mathrm{N}, 0^{\circ}-90^{\circ} \mathrm{E}$ & Fig. 8b & -0.79 & 99.9 \\
\hline
\end{tabular}

All time series are linearly detrended. The estimated effective confidence level $\left(s_{e}\right)$ and effective sample size $\left(N_{e}\right)$ accounting for the serial correlation in the time series are included

instability growth rate maximum (e.g., Hoskins and Valdes 1990)

$\sigma_{B I}=0.31\left|\frac{f}{N} \frac{\partial \mathbf{u}}{\partial z}\right|$.

The daily data are used to calculate seasonal averages (denoted by an overbar) of covariances between synoptic anomalies (denoted by a prime). The selected covariances include the storm track activity ${\overline{Z^{\prime} Z^{\prime}}}^{1 / 2}$, eddy kinetic energy $\left(\overline{u^{\prime} u^{\prime}}+\overline{v^{\prime} v^{\prime}}\right) / 2$, and the eastward and poleward components of the eddy heat flux, $\overline{u^{\prime} T^{\prime}}$ and $\overline{v^{\prime} T^{\prime}}$, respectively. Following Trenberth (1986), a 2-6 day high-pass filter with weights $\left[\begin{array}{lllllll}-1 & -3 & -5 & 18 & -5 & -3 & -1\end{array}\right] / 24$ is used to calculate the primed variables.

\subsection{Regression analysis}

The seasonal mean atmospheric fields are linearly detrended and then linearly regressed onto the AWT index. To assess the statistical significance of the correlation $r$ between the AWT index and local or area-averaged atmospheric anomalies, the probability that the correlation could be produced by random noise is estimated using a two-tailed Students's $t$ test. To account for the serial correlation in the time series, the statistical significance tests are carried out using an effective sample size $N_{e}$ instead of the actual sample size (24). The effective sample size is estimated using a formula based on Eq. (30) in Bretherton et al. (1999). A typical value of $N_{e}$ is 13-19. This is shown in Table 1, which also gives $r$ and its effective confidence level $\left(s_{e}\right)$ for the variables listed in the first column and discussed later.

Statistical field significance is estimated following the procedure introduced by Livezey and Chen (1983). First, local correlations of a given scalar field $F$ with the AWT index are obtained. Then, the total area $A_{F I}$ where these correlations are statistically significant at the
$95 \%$ confidence level is calculated for a given mapping domain. Next, the corresponding area $A_{F N}$ is obtained for 500 Monte Carlo trials in which the AWT index is replaced with a random time series. The random time series are constructed by shuffling the values of the AWT index. Finally, the field significance $s$ is calculated as percent of the Monte Carlo trials with $A_{F N}<A_{F I}$. The larger $s$ is, the lower the probability is that the observed pattern of significant correlations between $F$ and the AWT index occurred by chance. The same procedure is applied to estimate the field significance $s_{\lambda}$ and $s_{\phi}$ for the zonal and meridional components of the vector quantities, respectively.

For comparison, some atmospheric fields are also regressed onto the winter (DJFM) index of the NAO constructed by Hurrell (1995). The updated NAO index was downloaded from http://www.cgd.ucar.edu/cas/jhurrell/, and then linearly detrended and renormalized for the period under study. Some variables are also regressed onto the AWT index after subtracting the NAO-associated signal from these variables. To this end, the time series of a variable $X$ are replaced with the time series $X_{-\mathrm{NAO}}$ defined as $X_{-\mathrm{NAO}}=X-\mathrm{NAO} \times \operatorname{cov}(X, \mathrm{NAO})$, where $\operatorname{cov}(X, \mathrm{NAO})$ is the covariance between $X$ and the NAO index. In addition, regression patterns of winter SST anomalies are constructed using monthly mean fields of SST on a $1^{\circ}$ lattitude $\times 1^{\circ}$ longitude grid (Reynolds et al. 2002, downloaded from http://www.esrl.noaa.gov/psd/). Finally, the AWT index is correlated with two basic indices of SST variability in the Pacific, NINO3.4 and Pacific Decadal Oscillation (PDO). The NINO3.4 index (downloaded from http://www.cpc. ncep.noaa.gov/data/indices/sstoi.indices) is an oceanic measure (average of SST anomalies over the region $5^{\circ} \mathrm{S}$ $5^{\circ} \mathrm{N}$ and $120^{\circ} \mathrm{W}-170^{\circ} \mathrm{W}$ ) of the El-Niño-Southern Oscillation (ENSO). The PDO index (downloded from http://jisao. washington.edu/pdo/PDO.latest) is the leading principal component time series of monthly mean SST anomalies 
in the North Pacific, poleward of $20^{\circ} \mathrm{N}$ (e.g., Mantua et al. 1997).

\section{Results}

\subsection{Covariations between the summer AWT index and concurrent oceanic heat anomalies in the Nordic seas}

The summer AWT index used throughout this study is based on data from the relatively small BSO area (Fig. 1a). However, it is a climatically relevant index of oceanic variability. In the BSO area, the Atlantic water conveyed to the Nordic seas in the upper limb of the Atlantic meridional overturning circulation bifurcates into two branches. One branch turns eastward toward the Barents Sea (e.g., Smedsrud et al. 2013) and the other branch continues northward to Fram Strait (e.g., Walczowski and Piechura 2007; Beszczynska-Möller et al. 2012), and then to the Arctic Ocean (e.g., Rudels 2012; Polyakov et al. 2012). Some Atlantic water also recirculates from Fram Strait to the Greenland Sea (e.g., Schlichtholz and Houssais 2002).

The seasonal mean summertime AWT anomalies in the BSO area are representative of a coherent subsurface temperature variability on, at least, the regional scale. This is illustrated in Fig. 1a, which shows the difference in the composite mean of the summer ocean temperature in the 50-150 m layer in the Nordic seas region between the 'BSO warm summers' and 'BSO cold summers'. Positive differences corresponding to in-phase variations with the AWT index of up to about $1 \mathrm{~K}$ are found in a lobe spreading over the entire Barents Sea and around the Greenland Sea. A lobe of negative differences appears to the south. The differences are statistically significant at the $99 \%$ confidence level over most of the Nordic seas region (see the color shading in Fig. 1a). The broad northern lobe explains why a simultaneous wintertime reduction of the sea ice extent in the Barents and Greenland Seas is so strongly linked to warm AWT anomalies observed in the BSO area during the preceding summer (Schlichtholz 2011).

\subsection{Relationship to large-scale anomalies of air temperature and wind in the following winter}

Links of the large-scale atmospheric variability to oceanic heat anomalies in the Nordic seas are illustrated in Figs. 2 and 3. Figure 2 displays the AWT-associated winter anomalies of air temperature $T$ near the surface (at $1000 \mathrm{hPa}$ ) and average air temperature $T_{\Delta Z}$ in the entire troposphere (between 300 and $1000 \mathrm{hPa}$ ) north of $30^{\circ} \mathrm{N}$. Positive and negative anomalies of $T$ and $T_{\Delta Z}$ are plotted as red and blue contours, respectively. Anomalies that are statistically significant between the 90 and $95 \%$ confidence levels are marked through pink and aquamarine shading, respectively. Yellow shading denotes anomalies of any sign that are significant at the $95 \%$ or higher level. The corresponding anomaly patterns for geopotential height $Z$ (contours) and geostrophic wind $\mathbf{u}_{g}$ (arrows) at 1000 and $300 \mathrm{hPa}$ are shown in Fig. 3. The anomalies of $\mathbf{u}_{g}$ are plotted only at locations where either the zonal or meridional components are significant at the $90 \%$ or higher confidence level. Black arrows correspond to $\mathbf{u}_{g}$ with either of the components significant at the $95 \%$ or higher level. Gray arrows stand for $\mathbf{u}_{g}$ with one or both components significant between the 90 and $95 \%$ levels. The patterns in Figs. 2 and 3 correspond to the positive phase of the AWT index, that is, represent typical anomalous atmospheric conditions in winters following the summers with anomalously warm subsurface ocean temperature at the Barents Sea entrance. In the negative phase of the AWT index, the atmospheric anomalies have, by construction, the same patterns but opposite sign.

The AWT-associated local surface atmospheric variability in the Nordic seas area is characterized by large temperature anomalies in the marginal ice zone (Fig. 2a, see the thick black contour for the ice edge location) and strong anomalous winds along a northeastward extension of the climatological Icelandic Low, that is, in the IcelandBarents Sea corridor (Fig. 3a). In the positive phase of the AWT index, these winds blow into the Barents Sea along a common rim of an Arctic trough (negative height anomalies) and a sub-Arctic ridge (positive height anomalies) in the European sector (Fig. 3a). This 'Scandinavian' ridge extends significantly southeastward towards the Caspian Sea. It is one of three cells appearing in a crescent-like belt of positive height anomalies encircling the Arctic trough. The second ('East-Asian') ridge is found in eastern Asia. The third ('East-Pacific') ridge appears over the Gulf of Alaska. A similar crescent-like sub-Arctic ridge with three distinct cells around an Arctic through centered over the Canadian Archipelago is found in the upper troposphere (Fig. 3b).

The 'East-Pacific' ridge is equivalent barotropic, that is, exhibits geopotential height anomalies of a same sign in the upper and lower troposphere and a magnitude that decreases downward. The upper-tropospheric anomalies of $Z$ in this ridge and of the corresponding anticyclonic (clockwise) wind reach about $40 \mathrm{gpm}$ and $2.5 \mathrm{~m} \mathrm{~s}^{-1}$ per unit AWT index, respectively (Fig. 3b). In contrast, the two anticyclones over Eurasia exhibit a baroclinic structure in the lower troposphere manifested by their southward spreading at the surface underneath a mid-latitude uppertropospheric trough (Fig. 3). The westernmost cell of this trough, with significant cyclonic (counter-clockwise) wind anomalies around the Iberian Peninsula ('Iberian' trough), is equivalent barotropic. This is consistent with the general 
(a) $T(1000)$

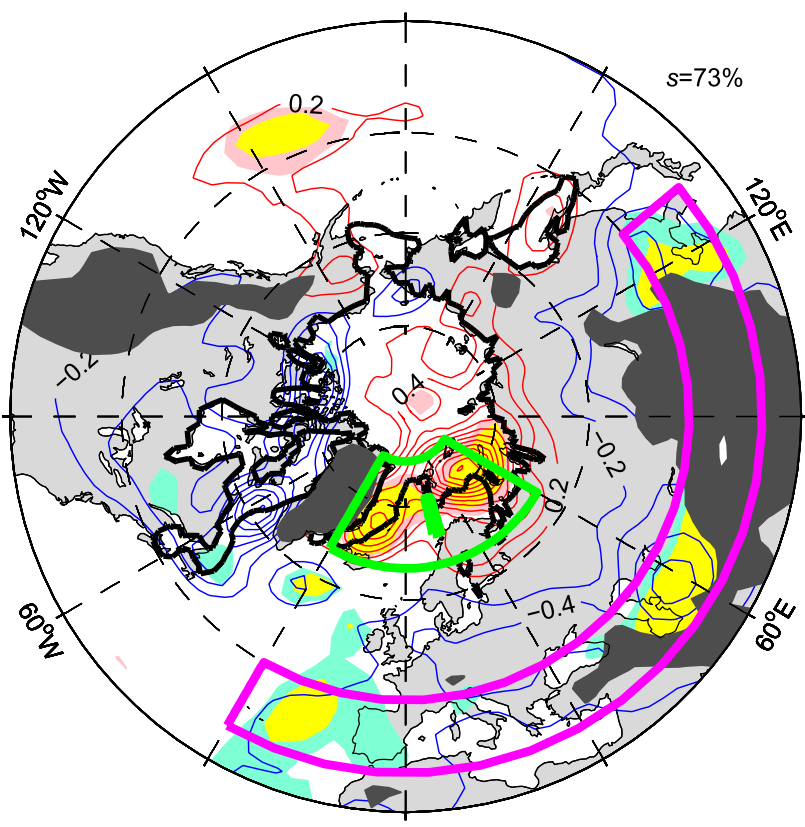

(b) $T_{\Delta Z}(300-1000)$

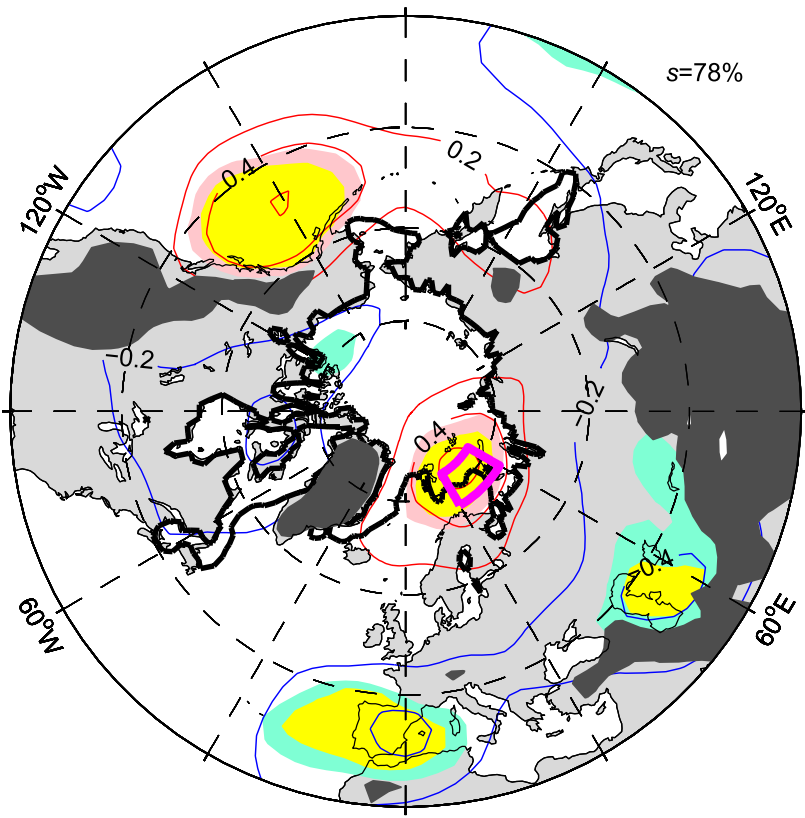

structure of wind variability in middle latitudes, characterized by barotropic profiles at the eastern ocean margins and baroclnic profiles over the continents (Blackmon et al. 1979).

The pattern of average tropospheric temperature anomalies exhibits two equally strong (about $0.6 \mathrm{~K}$ per unit AWT index) hot spots (localized warm anomalies) located over the Barents Sea and Gulf of Alaska (Fig. 2b). The deep Barents Sea hot spot and a weaker, shallow Greenland Sea hot spot (Fig. 2a) are driven by heating from below, and
4 Fig. 2 Winter (DJFM) anomalies of a air temperature $T$ at 1000 $\mathrm{hPa}$ and $\mathbf{b}$ average air temperature $T_{\Delta Z}$ in the layer $300-1000 \mathrm{hPa}$ regressed onto the previous summer (JJAS) AWT index. The red and blue contours represent positive and negative anomalies, respectively. The CI is $0.2 \mathrm{~K}$ per unit AWT index. The zero contour is omitted. Pink and aquamarine shading denote, respectively, positive and negative anomalies statistically significant between the 90 and $95 \%$ confidence levels. Anomalies significant at the $95 \%$ or higher confidence level are marked by yellow shading. The thick black line shows the climatological winter ice edge (15\% sea ice concentration contour). Dark shading masks areas with orography above $1000 \mathrm{~m}$. The values of $s$ on the right-hand side of the subplots are Monte Carlo estimates of field significance for the anomalies in the mapped area. In $\mathbf{a}$, the big and small green boxes delineate the Nordic seas and Barents Sea opening area, respectively. In $\mathbf{a}$ and $\mathbf{b}$, the magenta box delineates the area for averaging temperature (see Table 1 and Fig. 6c) and buoyancy frequency (see Fig. 6a), respectively

hence exhibit temperature anomalies that decrease with height. In contrast, the hot spot over the Gulf of Alaska has a weak surface signature, which reflects the equivalent barotropic character of the 'East-Pacific' anticyclone driven dynamically by upper-tropospheric processes. This hot spot is accompanied by a weaker, marginally significant cold spot in the Arctic trough.

Two major AWT-associated tropospheric cold spots are found over mid-latitude Eurasia, one in the 'Iberian' cyclone and another one in the Caspian Sea area (Fig. 2b). Both seem to be trapped by orography (see the dark shading in Fig. 2 for approximate location of mountain ranges), but their vertical structure differs. This is illustrated in Fig. 4, which displays a longitude-height cross-section of the AWT-associated winter anomalies of air temperature averaged between $35^{\circ}$ and $45^{\circ} \mathrm{N}$ (thin contours and color shading) on the background of the corresponding correlations (thick black contours) and approximate orography (dark shading). Consistent with the equivalent barotropic character of the 'Iberian' cyclone, significant temperature anomalies in the western cold spot occur in the entire troposphere and have the largest amplitude at mid-tropospheric levels. The cold spot in the Caspian Sea area is significant in most of the troposphere and exhibits extreme temperature anomalies of about $1 \mathrm{~K}$ per unit AWT index at the surface. Another cold spot appears in the Far East Asia (Fig. 2a), in the southernmost surface corner of the 'East-Asian' anticyclone (Fig. 3a). In this baroclinic zone significant temperature anomalies do not, however, extend beyond the boundary layer (Fig. 4). Noteworthy is also co-existence of the Eurasian tropospheric cold spots with warm air temperature anomalies in the lowermost stratosphere (Fig. 4), which indicates that the AWT-associated upper-level processes involve tropopause movements.

The shallow cold spot in the Far East Asia has an advective origin. This is suggested by a southward deflection of the anomalous low-level zonal winds impinging from east 
(a) $Z(1000), \mathbf{u}_{g}(1000)$

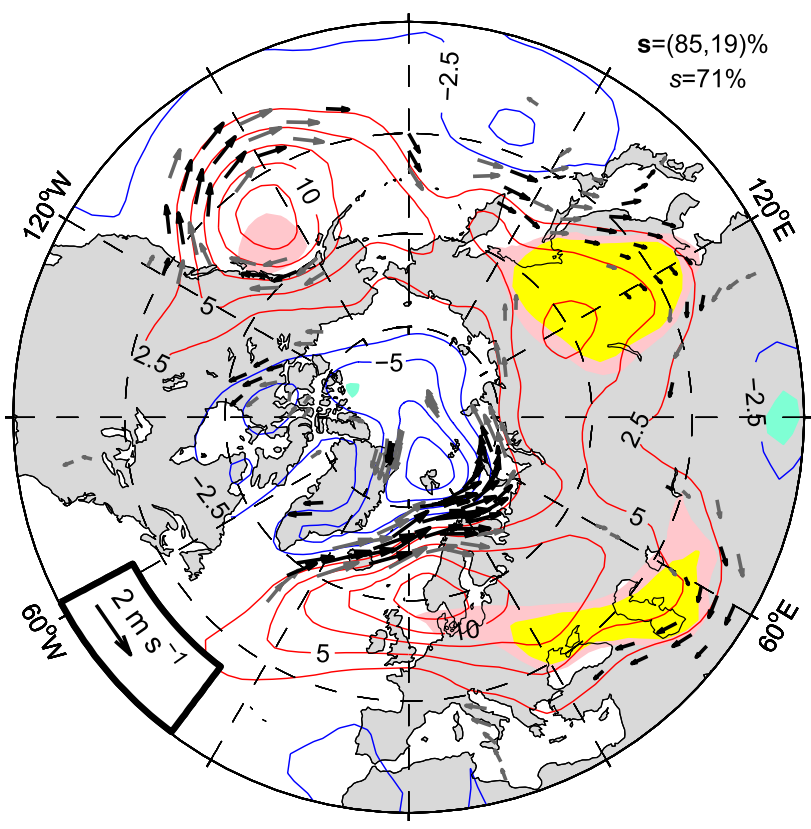

(b) $Z(300), \mathbf{u}_{g}(300)$

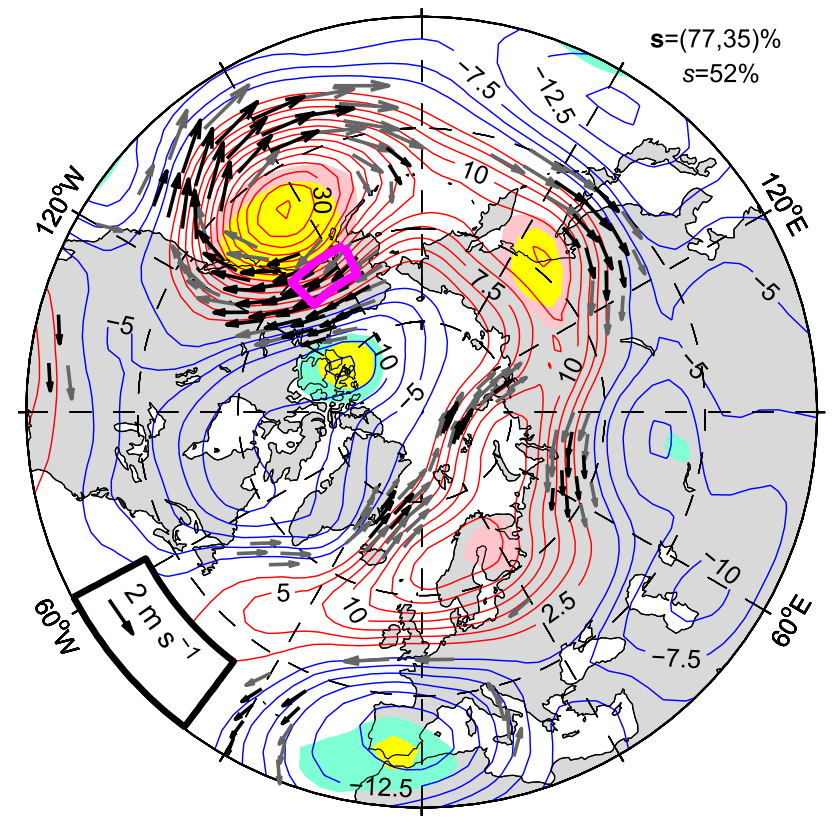

onto the Asian continent (Fig. 3a) and further supported by Fig. 5. In Fig. 5, the two Eurasian cold spots embedded in the baroclinic zones of the surface anticyclones (shading) are shown on the backround of the AWT-associated winter wind anomalies at $1000 \mathrm{hPa}$ (arrows) and the corresponding climatological mean of air temperature (thick contours). Evidently, the anomalous winds over the Far East Asia advect cold air southwestward, maintaining the observed cold anomaly. A southwestward advection
४Fig. 3 Winter anomalies of geopotential height $Z$ (contours and shading) and geostrophic wind $\mathbf{u}_{g}$ (arrows) at a $1000 \mathrm{hPa}$ and $\mathbf{b}$ $300 \mathrm{hPa}$ regressed onto the previous summer AWT index. The CI is $2.5 \mathrm{gpm}$ per unit AWT index. The contour and shading colors are explained in the caption to Fig. 2. The anomalies of $\mathbf{u}_{g}$ are in $\mathrm{m} \mathrm{s}^{-1}$ per unit AWT index (scaled as in the inlet, subsampled in longitude and masked if both components are nonsignificant at the $90 \%$ confidence level). Black arrows correspond to $\mathbf{u}_{g}$ with the zonal or meridional components significant at the $95 \%$ or higher confidence level. Gray arrows correspond to $\mathbf{u}_{g}$ with the zonal or meridional components significant between the 90 and $95 \%$ confidence levels but none of them significant at the $95 \%$ or higher confidence level. The values of $s$ and $\mathbf{s}=\left(s_{\lambda}, s_{\phi}\right)$ on the right-hand side of the subplots are Monte Carlo estimates of field significance for, respectively, $Z$ and the zonal and meridional components of $\mathbf{u}_{g}$ in the mapped area. In $\mathbf{b}$, the magenta box delineates the area for averaging zonal wind (see Table 1 and Fig. 6b)

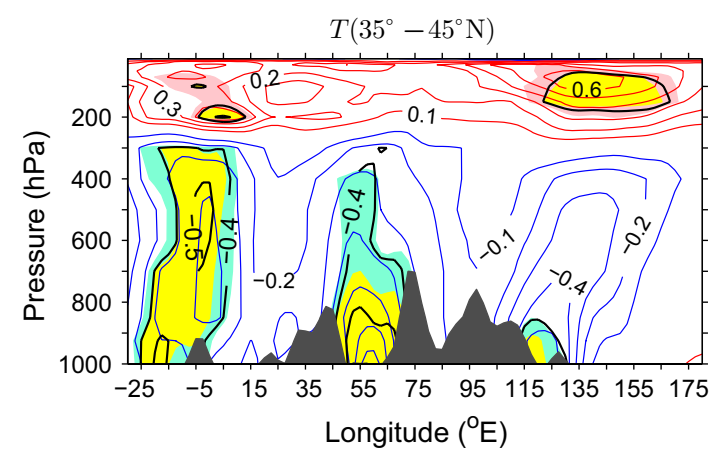

Fig. 4 Longitude-height cross-section of winter anomalies of air temperature averaged between $35^{\circ}$ and $45^{\circ} \mathrm{N}$ from $30^{\circ} \mathrm{W}$ to $180^{\circ} \mathrm{E}$ (thin contours and shading) regressed onto the previous summer AWT index. The CI is $0.1 \mathrm{~K}$ per unit AWT index. The thin contour and shading colors are explained in the caption to Fig. 2. The thick black contours are the correlation coefficients (only contours of $|r|>=0.4$ are plotted). Dark shading shows the orography at $40^{\circ} \mathrm{N}$

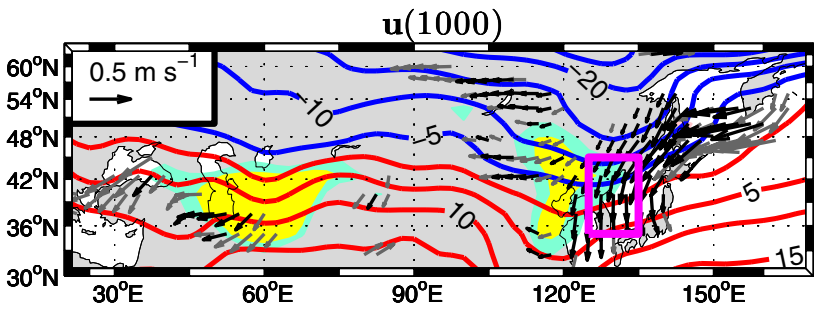

Fig. 5 Winter anomalies of wind velocity $\mathbf{u}$ at $1000 \mathrm{hPa}$ (in $\mathrm{m} \mathrm{s}^{-1}$ per unit AWT index; scaled as in the inlet) over mid-latitude Eurasia regressed onto the previous summer AWT index (arrows). The arrow colors are explained in the caption to Fig. 3 . The thick contours show winter climatology of air temperature at $1000 \mathrm{hPa}$ (in ${ }^{\circ} \mathrm{C}$; non-negative values in red and negative values in blue). The yellow and aquamarine shading corresponds to significant anomalies of air temperature at $1000 \mathrm{hPa}$ from Fig. 2a. The magenta box delineates the area for averaging meridional wind (see Table 1) 


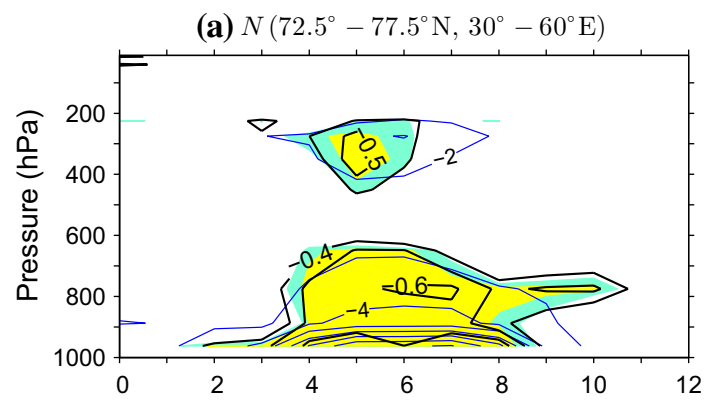

(b) $u\left(60^{\circ}-65^{\circ} \mathrm{N}, 205^{\circ}-225^{\circ} \mathrm{E}\right)$

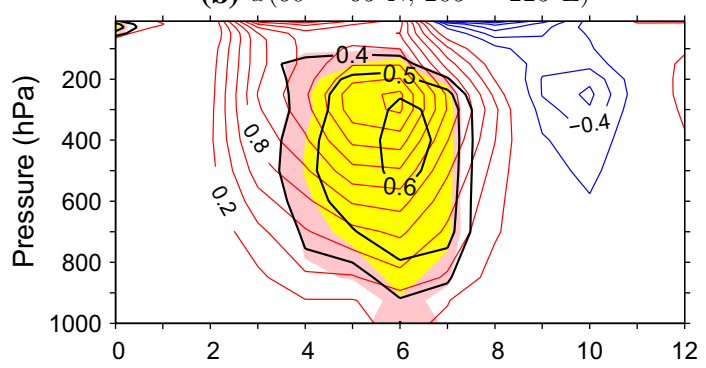

(c) $\mathrm{T}\left(35^{\circ}-45^{\circ} \mathrm{N}, 30^{\circ} \mathrm{W}-130^{\circ} \mathrm{E}\right)$

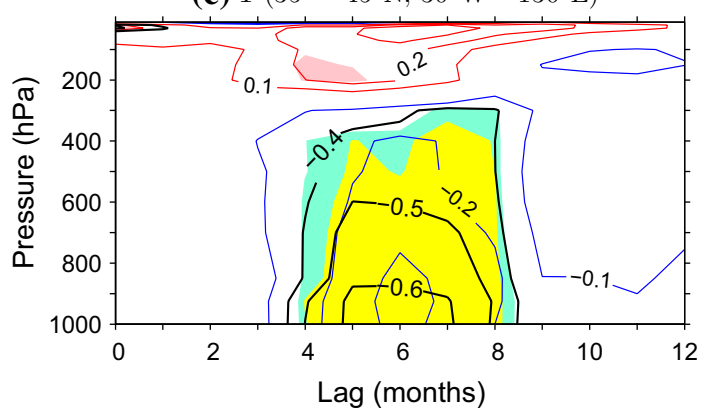

Fig. 6 Time-height development of the anomalies (thin contours and shading) of a buoyancy frequency averaged over the Barents Sea (magenta box in Fig. 2b), b zonal component (positive eastward) of the wind velocity averaged over Alaska (magenta box in Fig. 3b), and c air temperature averaged over mid-latitude Eurasia (magenta box in Fig. 2a) regressed onto the summer AWT index. In a-c, the CI is $2 \times 10^{-4} \mathrm{~s}^{-1}, 0.2 \mathrm{~m} \mathrm{~s}^{-1}$, and $0.1 \mathrm{~K}$ per unit AWT index, respectively. The thin contour and shading colors are explained in the caption to Fig. 2. The thick black contours are the correlation coefficients (only contours of $|r|>=0.4$ are plotted). Positive lags correspond to the AWT index leading the atmospheric variables calculated as 4-month averages with the interval of 1 month. Lags 0 and 6 months correspond to the summer (JJAS) and following winter (DJFM), respectively

of cold air by the anomalous winds drives also the cold spot in the Caspian Sea area or leads, at least, to its surface amplification. Amplification of surface anticyclones on intraseasonal time scales by upper-level processes in the presence of strong background temperature gradients is a known process contributing to, for instance, a strengthening of the cold Siberian High (Takaya and Nakamura 2005).

Temporal consistency of the local atmospheric response to oceanic forcing in the Nordic seas region
Table 2 Monte Carlo estimates of field significance $s$ for the anomalies of air temperature $(T)$ and zonal geostrophic wind $\left(u_{g}\right)$ at 1000 $\mathrm{hPa}$ in winter (DJFM) regressed onto the previous summer (JJAS) AWT index

\begin{tabular}{llll}
\hline Variable & Area & $s(\%)$ & $s_{-\mathrm{NAO}}(\%)$ \\
\hline$T$ & NH30 & 72 & $\mathbf{9 3}$ \\
$u_{g}$ & NH30 & 85 & $\mathbf{9 3}$ \\
$T$ & EA30 & 89 & $\mathbf{9 8}$ \\
$u_{g}$ & EA30 & $\mathbf{9 1}$ & $\mathbf{9 5}$ \\
\hline
\end{tabular}

The estimates are given for the whole area north of $30^{\circ} \mathrm{N}$ (NH30) and for its Eurasian sector between $30^{\circ} \mathrm{W}$ and $150^{\circ} \mathrm{E}$ (EA30). The corresponding field significance $s_{-\mathrm{NAO}}$ for the atmospheric anomalies left after removal of the part associated with the winter NAO index is also given. Significance greater than or equal to $90 \%$ (95\%) is in boldface (boldface and italic)

and remote atmospheric variability is checked in Fig. 6 . It displays selected area-averaged atmospheric anomalies regressed onto the summer AWT index (thin contours and shading) as a function of time (from lag 0 to lag 12 months) and pressure. The corresponding correlations are shown as thick black contours. Consistent with anomalous heating by the ocean, the vertical static stability anomalies averaged over the Barents Sea (magenta box in Fig. 2b) first appear at the surface in early autumn at lag 2 months (Fig. 6a). They spread throughout the lower troposphere in late autumn (lag 4 months) and reach extreme values at the surface from early to late winter (lags 5-7 months). In the same area, tropospheric temperature anomalies become significant at the surface in late autumn, reach the tropopause in early winter, and attain their largest amplitude and highest correlation with the AWT index at the surface in winter at lag 6 months (Schlichtholz 2014). Remote atmospheric anomalies evolve similarly. They generally become significant in late autumn and are best correlated with the AWT index in winter. This is shown in Fig. $6 \mathrm{~b}$ for the zonal wind in the Alaskan branch (magenta box in Fig. 3b) of the 'East-Pacific' anticyclone and in Fig. $6 \mathrm{c}$ for the air temperature over mid-latitude Eurasia. The temperature anomalies in Fig. 6c are averages over an area encompassing all Eurasian cold spots between $35^{\circ}$ and $45^{\circ} \mathrm{N}$ (magenta box in Fig. 2a). The maximum correlations of the AWT index with these averaged temperature anomalies and with the meridional wind anomalies on the southeastern rim of the 'East-Asian' anticyclone (averaged over the magenta box in Fig. 5) occur at $1000 \mathrm{hPa}$. These correlations as well as the correlation for the areaaveraged zonal wind at $300 \mathrm{hPa}$ over Alaska are included in Table 1.

Localised high correlations in remote regions do not automatically imply a casual link to oceanic conditions in the Nordic seas. However, the field significance calculated 
over the entire region mapped in Figs. 2 and 3 (see the numbers on the right-hand side of these figures) indicate that it is more unlikely than likely ( $s>50 \%$ or $s_{\lambda}>50 \%$ ) that all of the local anomalies significant at the $95 \%$ level are significant at this level by chance. Moreover, the field significance of the surface variables is higher if the Monte Carlo test is carried out for the Eurasian sector $\left(\phi \geq 30^{\circ} \mathrm{N}\right.$ and $\lambda$ between $30^{\circ} \mathrm{W}$ and $150^{\circ} \mathrm{E}$ ) alone. In this sector, the field significance of the surface variables is about $90 \%$ (see column $s$ in Table 2). This estimate of field significance is still moderate but, as discussed in Sect. 4.1, it may be too conservative.

\subsection{Relationship to storm tracks}

As mentioned in the introduction, observational and reanalysis data show that wintertime sea ice conditions in the Barents and Greenland Seas depend on earlier oceanic heat anomalies (Schlichtholz 2011; Nakanowatari et al. 2014). Synoptic reanalysis data reveal that wintertime sea ice anomalies in the Barents Sea affect surface conditions over Eurasia via modification of cyclonic pathways in the downstream region (Inoue et al. 2012). Numerical models show that the atmospheric response to wintertime Arctic sea ice anomalies depends on transient eddy feedbacks which, through nonlinear eddy fluxes of vorticity and heat, modify the local baroclinic response into an equivalent barotropic response of a hemispheric extent (e.g., Alexander et al. 2004; Deser et al. 2004). The same data as used here indicate that the AWT-associated convergences in eddy fluxes of heat and vorticity play an important role in the wintertime atmospheric heat and vorticity budgets over the Nordic seas (Schlichtholz 2014). Therefore, oceanic forcing in this region is likely to influence the large-scale weather systems and atmospheric circulation through eddy-mean flow feedbacks.

Large-scale weather systems originate mainly from baroclinic instabilities (e.g., Hoskins and Valdes 1990), a suitable measure of which is the Eady growth rate $\sigma_{B I}$ defined in Eq. (2). This parameter is proportional to the magnitude of the vertical shear of the horizontal wind and inversely proportional to the vertical static stability of the atmosphere. In the Nordic seas region, significant AWTassociated anomalous diabatic heating of the atmosphere starts in early autumn (Schlichtholz 2014) and leads to significant static stability anomalies that grow to winter (Fig. 6a). The reduced stability corresponding to anomalously warm ocean should trigger an earlier than normal onset of instability in baroclinic waves, leading to synoptic disturbances that affect the propagation of planetary waves and mean winds. The disturbed atmospheric circulation should then reorganize the eddy field, which should further

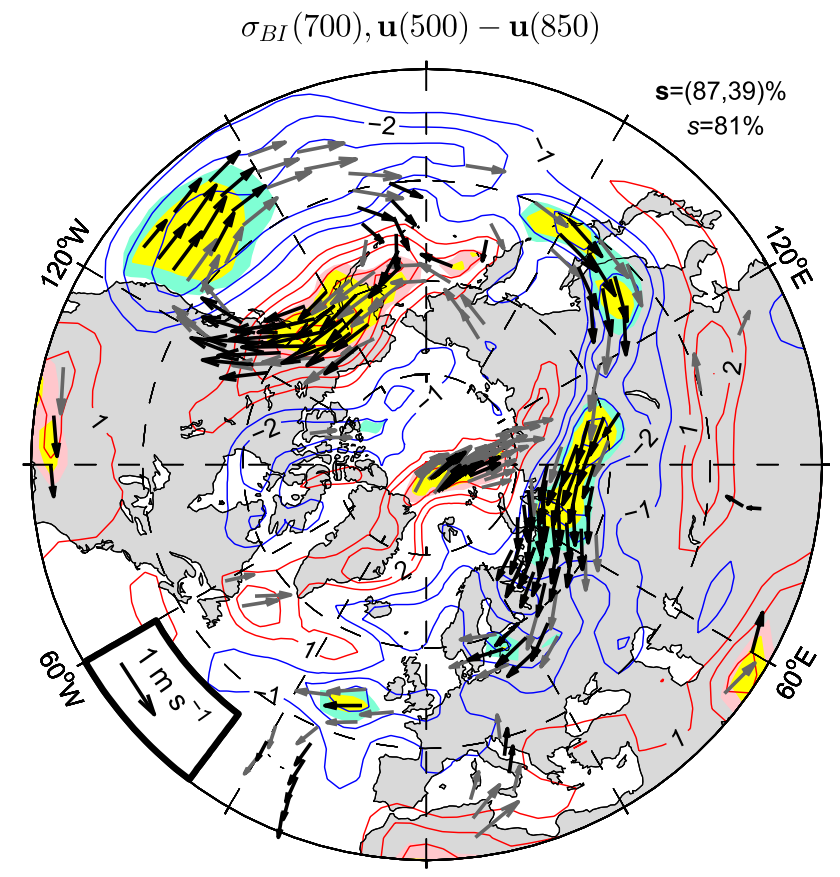

Fig. 7 As Fig. 3 except for winter anomalies of the Eady baroclinic instabilities growth rate maximum at $700 \mathrm{hPa}$ (contours and shading) and wind velocity difference between 500 and $850 \mathrm{hPa}$ (arrows). The $\mathrm{CI}$ is $1 \times 10^{-2}$ day $^{-1}$ per unit AWT index

modify the wind field. A similar scenario was proposed in the context of atmospheric links to August-September sea ice anomalies in the Siberian sector of the Arctic Ocean (Jaiser et al. 2012).

In the fully developed stage of eddy-mean flow interactions, the Eady growth rate depends strongly on the vertical shear of wind anomalies. This is illustrated in Fig. 7, which displays the AWT-associated winter anomalies of the wind velocity difference between 500 and $850 \mathrm{hPa}$ (arrows) on the background of the corresponding anomalies of $\sigma_{B I}$ at $700 \mathrm{hPa}$ (contours and shading). Warm AWT anomalies lead to a deeper than normal protrusion of the Atlantic zone of high baroclinicity into the Arctic, which is seen in Fig. 7 as a lobe of strengthened baroclinicity (positive anomalies of $\sigma_{B I}$ ) along the northern rim of the Nordic seas hot spots (Fig. 2). A general rule is that significant increase in the Eady growth rate, as in the Arctic lobe or a lobe over Alaska, corresponds to significant westerly anomalies of the vertical wind shear while significant decrease in the Eady growth rate, as in the southern elongated lobe that spreads over northern Eurasia and across the mid-latitude North Pacific, corresponds to significant easterly anomalies of the vertical wind shear. This indicates that oceanic forcing in the Nordic seas may indeed reorganize the storm tracks. To show that the latter are affected, Fig. 8a displays the AWT-associated winter anomalies of the storm track 
(a) $\overline{Z^{\prime} Z^{\prime}}{ }^{1 / 2}(250)$

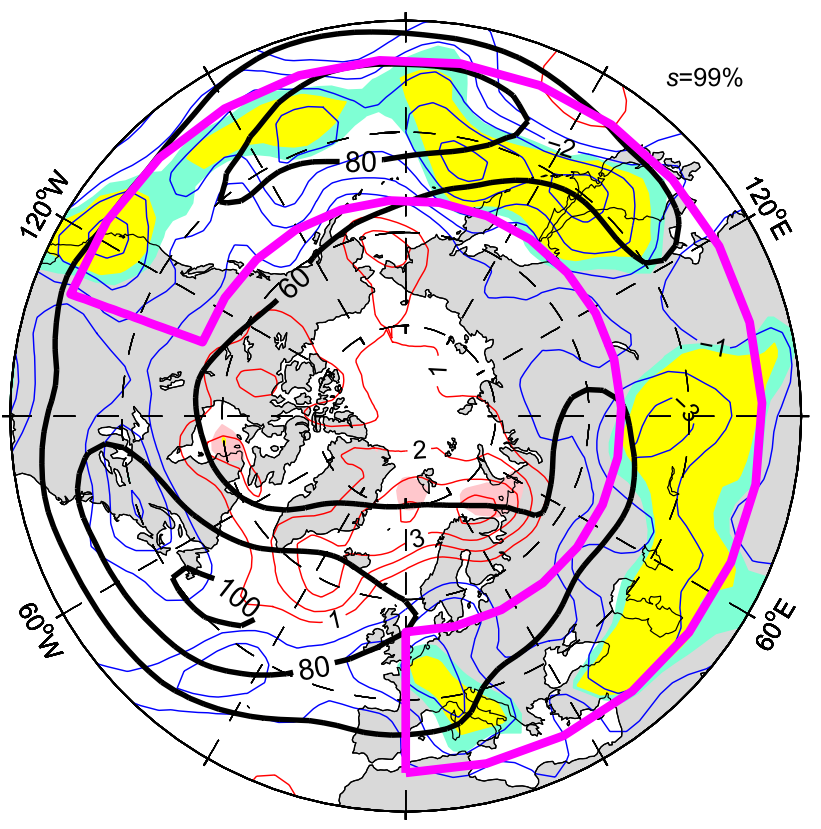

(b) $\overline{v^{\prime} T^{\prime}}(925)$

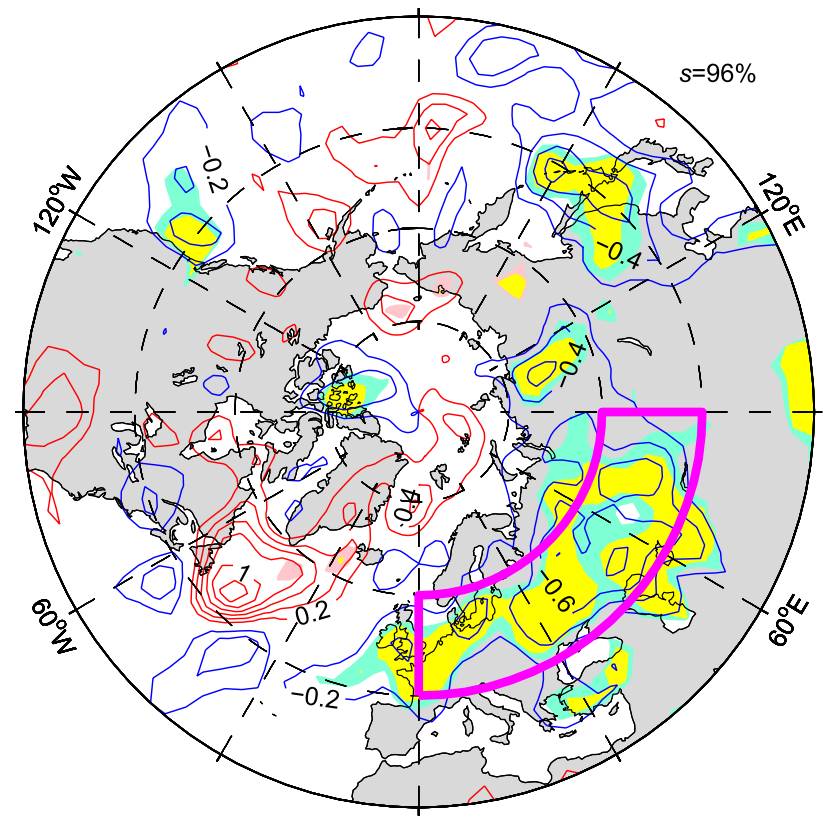

Fig. 8 As Fig. 2 except for winter anomalies of a storm track activity ${\overline{Z^{\prime} Z^{\prime}}}^{1 / 2}$ at $250 \mathrm{hPa}$ and $\mathbf{b}$ poleward synoptic eddy heat flux $\overline{v^{\prime} T^{\prime}}$ at $925 \mathrm{hPa}$. In $\mathbf{a}$ and $\mathbf{b}$, the CI is $1 \mathrm{gpm}$ and $0.2 \mathrm{~K} \mathrm{~m} \mathrm{~s}^{-1}$ per unit AWT index, respectively. In a, the thick black contours show winter climatology of ${\overline{Z^{\prime} Z^{\prime}}}^{1 / 2}$ (in gpm) at $250 \mathrm{hPa}$. In $\mathbf{a}$ and $\mathbf{b}$, the magenta box delineates the area for averaging ${\overline{Z^{\prime} Z^{\prime}}}^{1 / 2}$ and $\overline{v^{\prime} T^{\prime}}$ (see Table 1 and Fig. 9a, b), respectively

activity measured by the root mean square of the high-pass time-filtered geopotential height at $250 \mathrm{hPa}$ (thin contours and shading) on the background of the corresponding climatology of $\overline{Z^{\prime} Z^{\prime}}{ }^{1 / 2}$ (thick black contours).

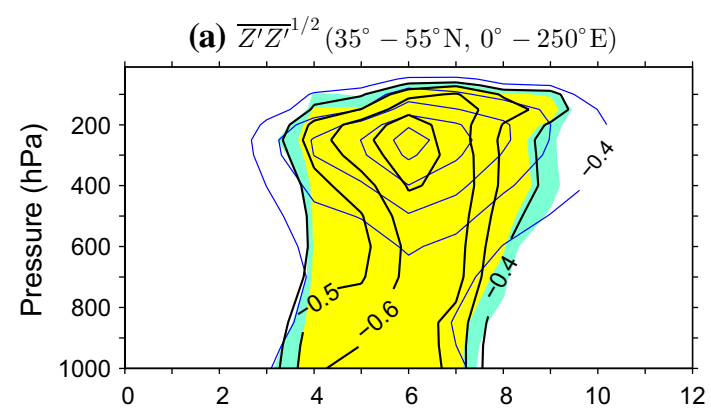

(b) $\overline{v^{\prime} T^{\prime}}\left(45^{\circ}-60^{\circ} \mathrm{N}, 0^{\circ}-90^{\circ} \mathrm{E}\right)$

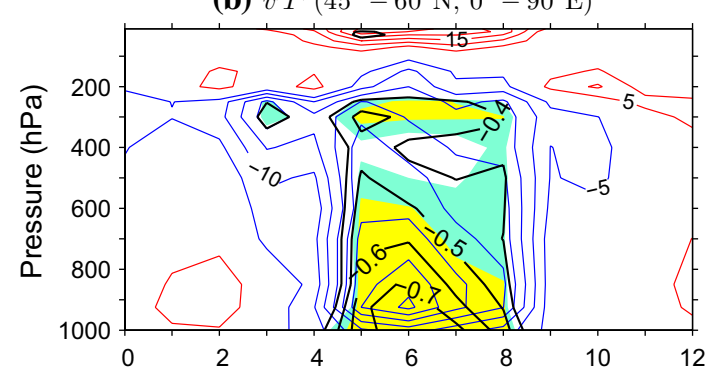

(c) $-\nabla_{h} \cdot \overline{\mathbf{u}^{\prime} T^{\prime}}\left(35^{\circ}-45^{\circ} \mathrm{N}, 30^{\circ} \mathrm{W}-130^{\circ} \mathrm{E}\right)$

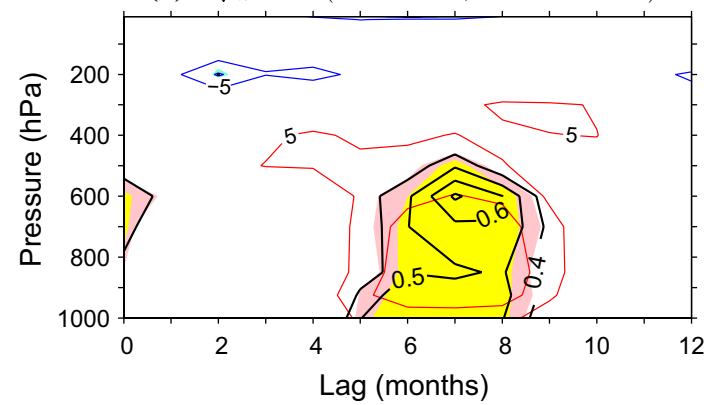

Fig. 9 As Fig. 6 except for the anomalies of a the storm track activity averaged over the mid-latitude Pacific and Eurasia (magenta box in Fig. 8a), b poleward synoptic eddy heat flux averaged over western Eurasia (magenta box in Fig. 8b), and c horizontal synoptic eddy heat flux convergence averaged over mid-latitude Eurasia (magenta box in Fig. 2a). In a-c, the CI is $0.4 \mathrm{gpm}, 5 \times 10^{-2} \mathrm{~K} \mathrm{~m} \mathrm{~s}^{-1}$ and $5 \times 10^{-3} \mathrm{~K} \mathrm{day}^{-1}$ per unit AWT index, respectively

The Atlantic storm track responds to warm AWT anomalies by a northeastward migration, seen in Fig. $8 \mathrm{a}$ as a strengthening of eddy activity (positive anomalies of ${\overline{Z^{\prime} Z^{\prime}}}^{1 / 2}$ ) over the Barents Sea and its weakening (negative anomalies of $\overline{Z^{\prime} Z^{\prime}}{ }^{1 / 2}$ ) over western Europe and the Caspian Sea area. Simultaneous changes are also observed in the Pacific storm track. A general rule is that the reduced eddy activity in middle latitudes corresponds to a slacking of the prevailing upper-level westerlies (easterly wind anomalies) while the intensified eddy activity in the Arctic region corresponds to a strengthening of the prevailing westerlies (Fig. 3b). Starting from late autumn, the eddy activity anomalies are significant throughout the troposphere and reach an extreme magnitude near the tropopause in winter. This is shown by the time-height development of the 
Table 3 Monte Carlo estimates of field significance $s$ for winter (DJFM) anomalies of synoptic eddy covariances regressed onto the previous summer (JJAS) AWT index

\begin{tabular}{lcl}
\hline Variable & $s(\%)$ & $p_{\mathrm{m}}(\mathrm{hPa})$ \\
\hline$\overline{Z^{\prime} Z^{\prime}}$ & 99 & 250 \\
$\left.\overline{\left(v^{\prime} v^{\prime}\right.}+\overline{u^{\prime} u^{\prime}}\right) / 2$ & 99 & 200 \\
$\overline{u^{\prime} T^{\prime}}$ & $\mathbf{9 9}$ & 250 \\
$\overline{v^{\prime} T^{\prime}}$ & 96 & 925 \\
\hline
\end{tabular}

The estimates are given for the whole area north of $30^{\circ} \mathrm{N}$ and for the pressure level $p_{\mathrm{m}}$ at which $s$ is maximum. The values of $s$ are in boldface and italic to emphasize that they all exceed $95 \%$

anomalies of ${\overline{Z^{\prime} Z^{\prime}}}^{1 / 2}$ averaged across the North Pacific and Eurasia (Fig. 9a), in the area where they are most significant (magenta box in Fig. 8a). The highest correlation of these averaged anomalies with the AWT index, occurring at $250 \mathrm{hPa}$, is included in Table 1.

Large mid-latitude lobes of significant AWT-associated winter anomalies are found not only in the storm track activity but also in other synoptic fields. In contrast to the anomalies of the storm track activity, eddy kinetic energy and zonal eddy heat flux, which all exhibit their highest field significance near the tropopause (200-250 hPa), the anomalies of the meridional eddy heat flux have their highest field significance at $925 \mathrm{hPa}$. This is shown in Table 3, which gives the values of $s$ for the entire area north of $30^{\circ} \mathrm{N}$ at the levels at which these values are the largest in winter. Locally, the most significant anomalies of $\overline{v^{\prime} T^{\prime}}$ at $925 \mathrm{hPa}$ occur over Eurasia and in the entrance area of the Pacific storm track (Fig. 8b). In both regions, the anomalies of $\overline{v^{\prime} T^{\prime}}$ are negative indicating a reduction of the poleward eddy heat flux during the positive phase of the AWT index. As in the case of $\overline{Z^{\prime} Z^{\prime}}{ }^{1 / 2}$, the anomalies of $\overline{v^{\prime} T^{\prime}}$ are extreme and most significant in winter. This is illustrated in Fig. 9b, which displays the time-height development of the anomalies of $\overline{v^{\prime} T^{\prime}}$ in western Eurasia, averaged over the magenta box in Fig. 8b. The maximum correlation of the AWT index with these averaged anomalies, occurring at $925 \mathrm{hPa}$, is included in Table 1.

The vertical gradient of $\overline{v^{\prime} T^{\prime}} / S$, where $S$ is the static stability of a basic state, represents a baroclinic forcing of the zonal flow. An analogous baroclinic forcing is exerted on the meridional flow by the vertical gradient of $-\overline{u^{\prime} T^{\prime}} / S$ (e.g., Trenberth 1986). Therefore, the anomalous eddy heat fluxes may contribute to the wind anomalies maintaining the surface cold spots over Eurasia (Figs. 2a and 5). At the same time, these fluxes tend to destroy the cold spots. Their restoring effect on temperature anomalies is illustrated in (a) $Z(850)$ on $\mathrm{NAO}, \mathbf{u}_{g}(850)$ on $\mathrm{AWT}$

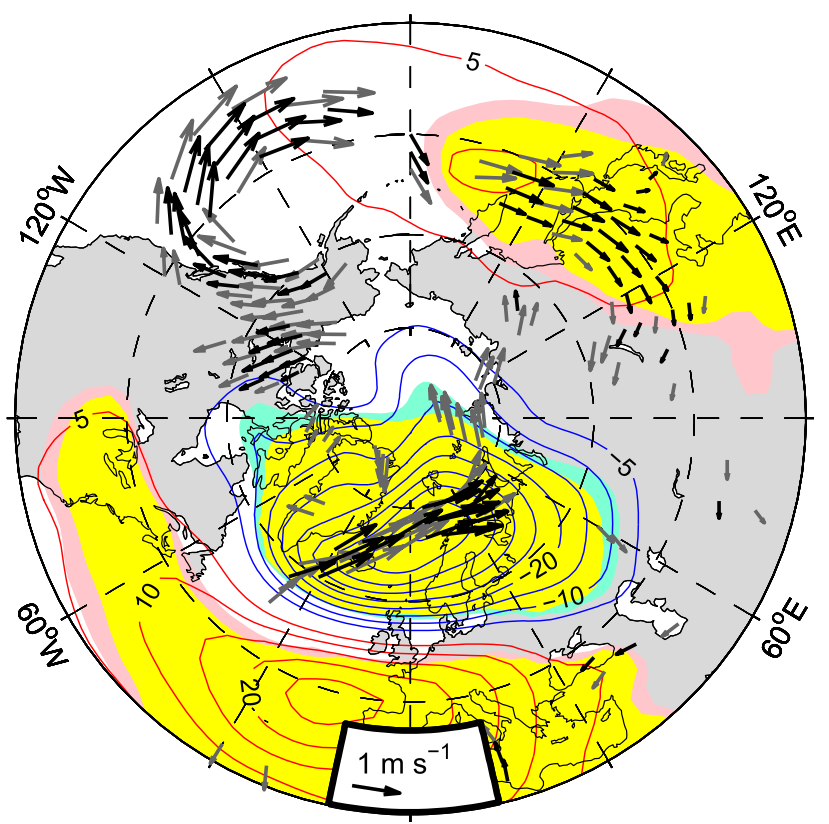

(b) $T_{\Delta Z}(850-1000)$ on NAO and AWT

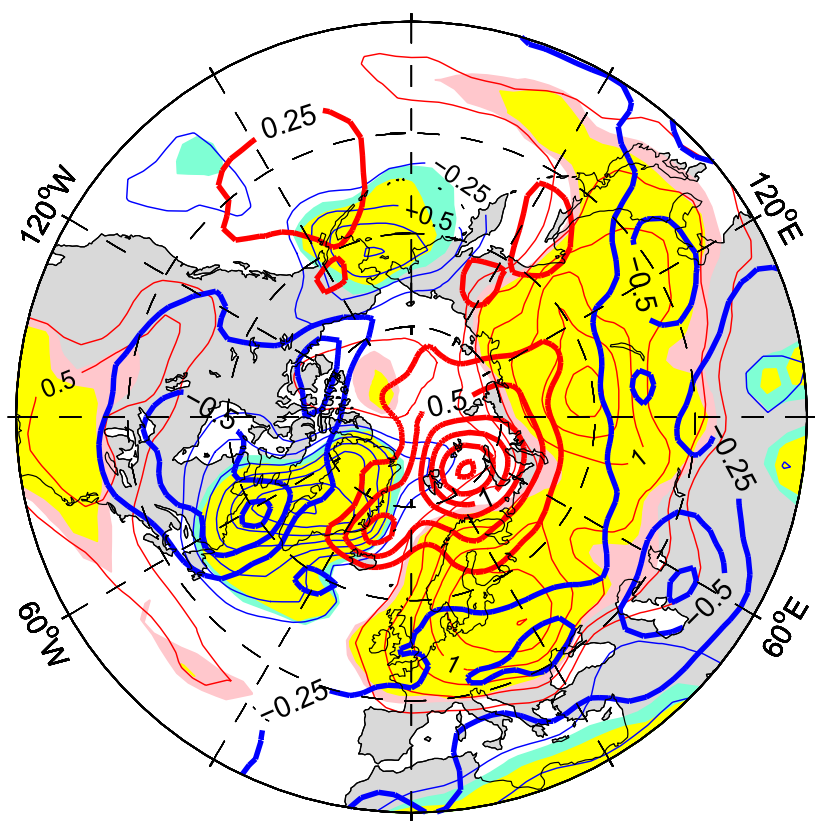

Fig. 10 Comparison of winter (DJFM) atmospheric anomalies regressed onto the concurrent NAO index and previous summer (JJAS) AWT index: a NAO-associated geopotential height (thin contours and shading) and AWT-associated geostrophic wind (arrows; color convention as in Fig. 3) at $850 \mathrm{hPa}$, and $\mathbf{b}$ average air temperature in the layer $850-1000 \mathrm{hPa}$ associated with the NAO (thin contours and shading) and AWT (thick contours with CI of $0.25 \mathrm{~K}$ per unit AWT index). In $\mathbf{a}$ and $\mathbf{b}$, the CI for the thin contours is $5 \mathrm{gpm}$ and $0.25 \mathrm{~K}$ per unit NAO index, respectively. The contour and shading color convention as in Fig. 2 
Table 4 Correlation of winter (DJFM) indices of the North Atlantic Oscillation (NAO), El-Niño (NINO3.4) and Pacific Decadal Oscillation (PDO) with the previous summer (JJAS) AWT index and the concurrent (DJFM) atmospheric variables significantly correlated with the AWT index and listed in Table 1, that is, area-averaged air temperature $(T)$ at $1000 \mathrm{hPa}$ in mid-latitude Eurasia, meridional wind (v) at $1000 \mathrm{hPa}$ in the Far East Asia, zonal wind $(u)$ at $300 \mathrm{hPa}$ over Alaska, synoptic storm track activity $\left(\bar{Z}^{\prime} Z^{\prime} 1 / 2\right)$ at $250 \mathrm{hPa}$ over midlatitude Eurasia and North Pacific, and poleward synoptic eddy heat flux $\left(\overline{v^{\prime} T^{\prime}}\right)$ at $925 \mathrm{hPa}$ in western Eurasia

\begin{tabular}{llrrrrr}
\hline & AWT & \multicolumn{1}{l}{ T } & $v$ & $u$ & $\overline{Z^{\prime} Z^{\prime}}$ \\
\hline NAO & -0.06 & 0.25 & 0.27 & 0.05 & 0.06 & 0.00 \\
NINO3.4 & -0.08 & 0.08 & 0.20 & -0.35 & 0.18 \\
PDO & -0.14 & -0.24 & -0.17 & $-\mathbf{0 . 4 8}$ & -0.03 & -0.01 \\
\hline
\end{tabular}

All time series are linearly detrended. Correlations significant at the $90 \%$ (95\%) or higher confidence level are in boldface (boldface and italic)

Fig. 9c. It shows the time-height development of the anomalous horizontal eddy heat flux convergence $-\nabla_{h} \cdot \overline{\mathbf{u}^{\prime} T^{\prime}}$ averaged over the magenta box in Fig. $2 \mathrm{a}$, that is, over the same area as used in averaging the temperature anomalies shown in Fig. 6c. Clearly, cold anomalies persist in spite of the significant warming tendency owing to anomalous eddy heat flux convergence.

\section{Discussion}

\subsection{Link to the North Atlantic Oscillation}

While it is commonly recognized that the ocean plays a key role in the tropical climate variability, the NAO has long been regarded as being principally driven by internal atmospheric dynamics and, consequently, as being largely unpredictable from the sea surface temperature on the seasonalto-interannual time scale (e.g., Kushnir et al. 2006). There is, however, growing evidence that some seasonal predictability of the winter NAO exists owing to its response to slow changes in other boundary conditions, the continental snow cover (e.g., Cohen and Jones 2011; Orsolini et al. 2013) and Arctic sea ice extent (e.g., Wu and Zhang 2010; Li and Wang 2013) in particular. Latest seasonal forecast systems provide new evidence that the winter NAO and, consequently, many aspects of European and North American winter climate are highly predictable months ahead (e.g., Scaife et al. 2014; MacLachlan et al. 2014). The predictable signal in the NAO arises from teleconnections to tropical phenomena, such as ENSO and the quasi-biennial oscillation in the lower stratosphere, and also to anomalies in the North Atlantic Ocean heat content in the subpolar gyre and sea ice extent in the Kara Sea (Scaife et al. 2014).

The NAO not only controls large-scale atmospheric conditions, but it also influences oceanic variability. In particular, our summer AWT index is significantly linked to the NAO index of previous winters (Schlichtholz and Houssais 2011). However, it is not correlated with the NAO index of the following winter $(r=-0.06)$. Consequently, the climatic impacts associated with the high-latitude ocean variability are complementary to the concurrent impacts of the NAO. Indeed, spatial patterns of AWT-associated anomalies appear in quadrature with the concurrent NAOassociated anomalies. An example is shown in Fig. 10a where the AWT-associated winter anomalies of geostrophic wind at $850 \mathrm{hPa}$ (arrows) are superimposed onto the corresponding NAO-associated anomalies of geopotential height (contours and shading). Another example is given in Fig. 10b where the AWT-associated winter anomalies of average temperature between 850 and $1000 \mathrm{hPa}$ (thick contours) are compared with the corresponding NAO-associated anomalies (thin contours and shading). Removing the NAO-associated signal from the original atmospheric time series yields quite high estimates (about 95\%) of the field significance for the AWT-associated surface climate variables (see column $s_{-\mathrm{NAO}}$ in Table 2). Consistent with these findings, none of the wintertime area-averaged atmospheric variables that are strongly linked to the previous summer AWT index (listed in Table 1) are significantly correlated with the concurrent NAO index (see Table 4, upper row).

\subsection{Comparison with some studies of atmospheric links to anomalous sea ice cover in the Barents Sea}

We have shown that a wintertime "warm Arctic-cold Eurasia' pattern of surface air temperature emerges in the positive phase of the AWT index (Fig. 2). Similar patterns are also a characteristic of wintertime atmospheric response to Arctic sea ice reduction, to sea ice reduction in the Barents and Kara Seas in particular (e.g., Honda et al. 2009; Petoukhov and Semenov 2010; Kim et al. 2014). The continental lobe of these patterns is typically located farther north than the AWT-associated cold spots. Several studies associate this lobe with a negative phase of the Arctic Oscillation (a hemispheric counterpart of the NAO) promoted by the sea ice deficit (e.g., Kim et al. 2014). As shown in the previous section, the AWT-associated atmospheric anomalies are decoupled from the NAO, both in time and space. A distinct character of these anomalies may reflect a particular 
timing and/or location at which the ocean affects sea ice, which is also influenced by independent atmospheric drivers. For instance, the difference in composite means of the November-December sea ice concentration investigated by Kim et al. (2014, their Fig. 1) in relation to the largescale atmospheric circulation exhibits in-phase and equally strong anomalies in the Barents and Kara Seas. By contrast, anomalously warm AWT in the BSO area corresponds to sea ice reduction in the Barents and Greenland Seas, and no sea ice anomalies in the Kara Sea (Schlichtholz 2014, his Fig. 3). Moreover, the sea ice anomalies in the composite field of Kim et al. (2014) spread zonally along the northern part of the Barents Sea while in the AWT-associated pattern they mainly appear in the eastern part of the Barents Sea. This seemingly small detail may be essential since the leading mode of wintertime variability in the Barents Sea ice cover exhibits a zonal monopole in the northern Barents Sea that is driven by anomalous meridional winds (Herbaut et al. 2015). Such winds rather precede than follow the summertime AWT anomalies in the BSO area (Schlichtholz and Houssais 2011; Schlichtholz 2013).

We have identified, based on an Eulerian method, strong links of wintertime storm tracks to the AWT anomalies. In particular, when the AWT anomaly is positive, the poleward synoptic eddy heat flux increases in the northern part of the Atlantic storm track and decreases over western Eurasia (Fig. 8b). This spatial pattern of synoptic heat flux changes corresponds qualitatively to the northward shift of the storm track in the Nordic seas region related to light ice conditions in the Barents Sea. Such a shift was demonstrated by Inoue et al. (2012) based on data from a cyclone identification and tracking algorithm applied to 6-hourly sea level pressure from the NCEP/NCAR reanalysis. The composite anomalies of wintertime synoptic cyclone characteristics and the corresponding anomalies of the mean sea level pressure and air temperature investigated by Inoue et al. (2012) led these authors to the conclusion that the northward shift in the cyclone paths triggered by reduction in the Barents Sea ice cover is a driving mechanism for the anomalous atmospheric circulation that maintains the 'warm Arctic-cold Eurasia' anomaly. The centers of action in the anomaly patterns shown by Inoue et al. (2012) and here appear at slightly different locations. For instance, the anomalous continental high associated with the sea ice decline in the Barents Sea extends from the coastal area of Siberia to Scandinavia (Inoue et al. 2012, their Figs. 3a and 7a) while the corresponding AWT-associated high is more significant in two distinct cores located farther south (Fig. 3a). Such discrepancies may again be attributed to somewhat different ocean boundary conditions in the two cases.

In a recent study, based on observations in the 19792013 period and climate model simulations, Mori et al.
(2014) show that the two leading modes of the winter (DJF) mean air temperature variability in the Eurasian sector $\left(20^{\circ}\right.$ $-90^{\circ} \mathrm{N}, 0^{\circ}-180^{\circ} \mathrm{E}$ ) correspond to the NAO thermal pattern and the 'warm Arctic-cold Eurasia' pattern, respectively, and that the principal component time series of the latter mode is highly correlated $(r=-0.81)$ with the area-averaged anomalies of sea ice concentration in the Barents and Kara Seas. They also show that the 'warm Arctic-cold Eurasia' mode stayed persistently in its positive phase after the winter 2004/2005 and that it is more likely that this mode rather than the NAO was responsible for increased frequency of severe winters in recent years. The positive phase of the 'warm Arctic-cold Eurasia' mode exhibited the largest amplitude in winters 2004/2005, 2005/2006 and 2011/2012 (Mori et al. 2014, their Fig. 2). The first two of these winters followed the two summers (2004 and 2005) with the highest AWT in the entire 1982-2005 record (Fig. 1b). Therefore, it is possible that oceanic forcing contributed to the cold Eurasian winters in 2004/2005 and 2005/2006.

Herbaut et al. (2015) argue that the impact of the ocean on the Barents Sea ice cover diminished after 2004 when an abrupt northward retreat of the ice margin occurred. However, their time series of observed winter (JFM) sea ice anomalies in the northeastern Barents Sea over the period 2005-2012 evolves consistently with their index of observed AWT in the BSO during the preceding winter, except for the winter 2012. A strong anomalous sea ice decline in that winter was preceded by a negative AWT anomaly in the winter 2011 (Herbaut et al. 2015, their Fig. 18c; note that the AWT index shown in that figure has the opposite sign to the actual temperature anomalies). The latter discrepancy does not exclude the ocean from potential drivers of the extremely strong 'warm Arctic-cold Eurasia' mode in the winter 2011/2012. A warm oceanic anomaly might have been generated by air-sea interactions downstream of the BSO area during the late winter 2011, which could then inhibit sea ice formation in the following winter. The abnormal sea ice decline in the winter 2011/2012 and the corresponding extreme cold in Eurasia might as well have been triggered by remote oceanic forcing from the North Atlantic through the mechanism proposed by Sato et al. (2014) (see the section below).

\subsection{Link to anomalies of sea surface temperature in the North Atlantic}

In addition to the anomalies driven by oceanic influences on sea ice, the AWT-associated atmospheric variability may include a signal forced in the open water areas of the ocean, in the Nordic seas or elsewhere. This possibility is suggested by the pattern of the AWT-associated winter SST anomalies in the North Atlantic/Nordic seas region (Fig. 11a). The pattern exhibits a lobe of positive anomalies 
(a) SST on AWT

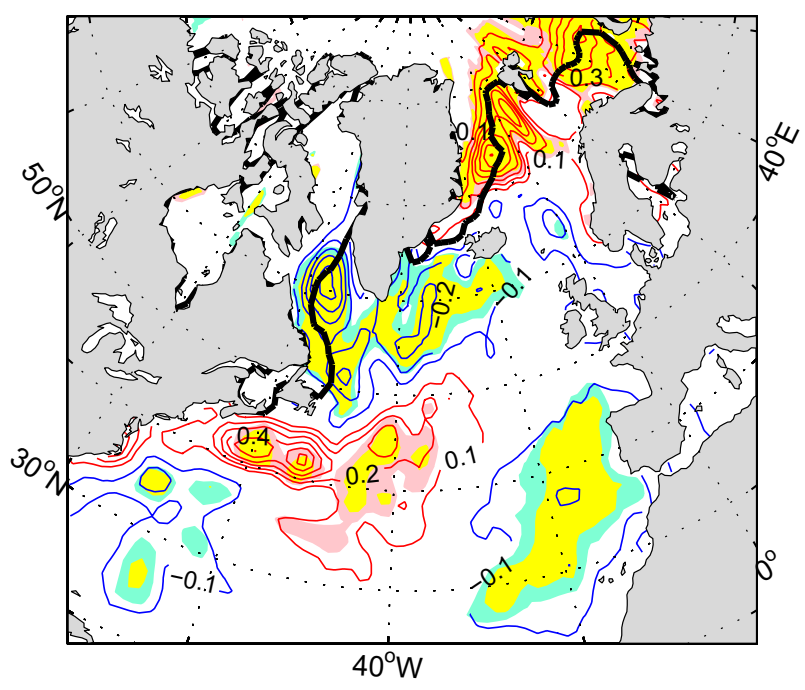

(b) $\mathrm{SST}$ on $\overline{v^{\prime} T^{\prime}}$

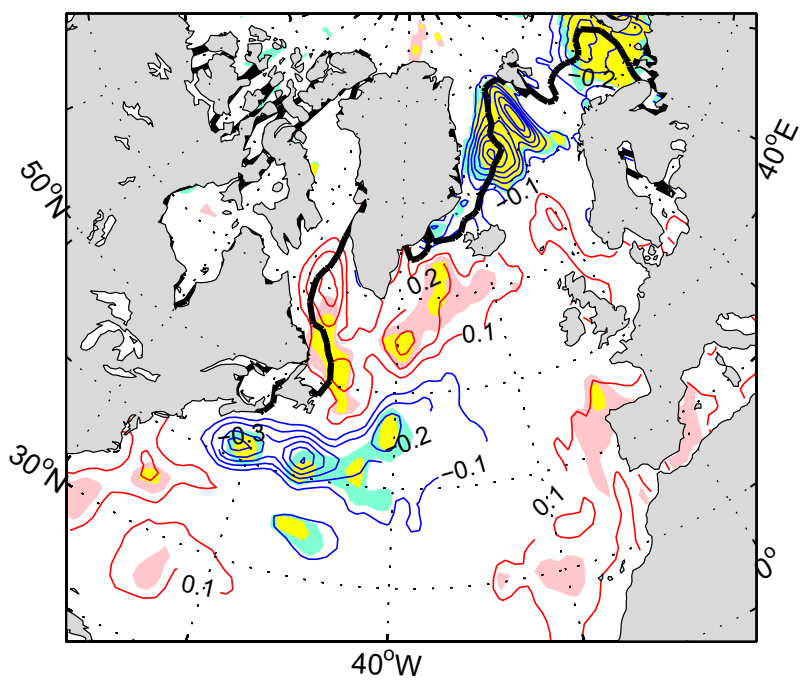

Fig. 11 As Fig. 2 except for winter anomalies of sea surface temperature in the North Atlantic/Nordic seas region regressed onto a the previous summer AWT index and $\mathbf{b}$ the concurrent poleward synoptic eddy heat flux averaged over the magenta box in Fig. 8b. In a and b, the CI is $0.1 \mathrm{~K}$ per unit AWT index and per 1 standard deviation of the averaged $\overline{v^{\prime} T^{\prime}}$, respectively

in the Nordic seas and another lobe in the Gulf Stream area. The two lobes are separated by a lobe of negative anomalies in the subpolar region. Weaker lobes of negative anomalies appear also to the south and east of the Gulf Stream area. Maximum local correlations with the AWT index are higher in the Nordic seas and the subpolar gyre $(|r|>0.8)$ than in the other lobes $(|r|<0.6)$.

The SST anomaly pattern in Fig. 11a is consistent with a study by Sato et al. (2014) based on the NCEP CFSR data. These authors suggest that poleward shift of an SST front over the Gulf Stream induces warm southerly advection and consequent sea ice reduction over the Barents Sea, and a cold anomaly over Eurasia via planetary waves triggered over the Gulf Stream region. The sea ice anomaly in the Barents Sea then amplifies locally the warm advective anomaly, promoting a 'warm Arctic-cold Eurasia' pattern. This mechanism may be complementary to the forcing by oceanic heat anomalies in the Nordic seas. Indeed, the composite sea ice drift and sea level pressure anomaly patterns for December which Sato et al. (2014, their Figs. 1 and 2) show in support of their hypothesis do not correspond to the AWT-associated surface wind pattern (Fig. 3a). They correspond to meridional wind anomalies over the entire Nordic seas region while the AWT-associated winds have a strong zonal component in the BSO area.

The south-westerly and westerly surface winds in the Iceland-Barents Sea corridor associated with positive AWT anomalies (Fig. 3a) imply increased wind-driven inflow to the Barents Sea (e.g., Ingvaldsen et al. 2004) and thus a positive feedback that can enhance the heat transport. Such a positive feedback has been suggested as an amplifier of climate variability in the Barents Sea region (e.g., Ådlandsvik and Loeng 1991; Schlichtholz 2013) and the whole Arctic (e.g., Bengtsson et al. 2004; Semenov et al. 2009). The present study indicates that this feedback may also contribute to the 'warm Arctic-cold Eurasia' pattern and wintertime atmospheric variability in other regions as well. Schlichtholz (2013) postulated that oceanic heat anomalies that trigger this feedback are to a large extent formed in the deep mixed layer by local air-sea interactions in the Nordic seas during the winter/spring season and reemerge on the surface during the following autumn/winter season. A strong influence of reemerging SST anomalies on the wintertime sea ice cover in the Nordic seas was highlighted by Schlichtholz (2011) and corroborated by Nakanowatari et al. (2014). Nakanowatari et al. (2014) argued, based on the same dataset as used by Sato et al. (2014), that oceanic heat anomalies that reemerge on the surface in the Barents Sea originate mainly from the subpolar gyre in the North Atlantic, from where they are advected to the BSO area in about three years. Evidently, a further research is needed to quantify local and remote contributions to the climate feedbacks in the Nordic seas region and their role in shaping the large-scale atmospheric variability.

The scenario in which the large-scale atmospheric anomalies investigated here are to a large extent driven by oceanic forcing in the Nordic seas region is consistent with the co-variability of the winter SST anomalies with the atmospheric anomalies related most significantly to the previous summer AWT index. As an example, Fig. 11b displays the pattern of winter SST anomalies in the North Atlantic/Nordic seas region regressed onto the concurrent poleward eddy heat flux in western Eurasia (averaged over the magenta box in Fig. 8b). The pattern mirrors the 
corresponding pattern of the AWT-associated SST anomalies (Fig. 11a). The strongest lobe in both patterns is the one in the Greenland Sea. The maximum local correlation of the SST anomalies in this area with the averaged eddy heat flux in western Eurasia is as high as -0.84 .

\subsection{Link to air-sea interaction over the North Pacific}

While the regional response in the Atlantic-European sector described by Schlichtholz (2014) is directly related to AWT and associated surface heat flux anomalies, the remote response in the North Pacific domain may as well be linked to the local forcing. While a thorough investigation of this problem is beyond the scope of the present study, a few comments on possible links to air-sea interaction over the North Pacific are given below. To begin with we recall that winter weather in the extratropical North Pacific sector depends strongly on ENSO, a coupled ocean-atmosphere phenomenon in the tropical Pacific that is the dominant mode of interannual variability globally (e.g., Rasmusson and Wallace 1983). The ENSO teleconections are also major drivers of SST anomalies in the extratropical North Pacific (e.g. Alexander et al. 2002). The AWT index is, however, not correlated with either ENSO $(r=-0.08$ for the following winter NINO3.4 index) or the related dominant mode of SST variability in the extratropical North Pacific ( $r=-0.14$ for the following winter PDO index). Neither the wintertime area-averaged atmospheric variables that correlate highly with the previous summer AWT index (listed in Table 1) are significantly linked to the concurrent NINO3.4 or PDO indices, except for the zonal wind over Alaska (Table 4). The latter is significantly, albeit moderately $(r=-0.48)$, related to the PDO.

Some atmospheric anomalies in the North Pacific domain and beyond may be driven by regional SST anomalies that are not linked to the concurrent ENSO or PDO (e.g. Frankignoul and Sennéchael 2007). Such anomalies may arise from, for instance, meridional shifts of the Kuroshio/Oyashio extensions. However, the strongest upper-tropospheric center of action associated with these shifts appears over the western North Pacific (Frankignoul et al. 2011, their Fig. 8). In contrast, the strongest center of action in the AWT-associated upper-level geopotential height anomalies is found over the Gulf of Alaska (Fig. 3b).

An abnormal ridge over the Gulf of Alaska is a recurrent feature that may lead to persistent regional weather perturbations, such as droughts in California by blocking the storms. A particularly strong event of this type was observed in winter 2013/2014. Wang et al. (2014) attributed this event to an ENSO precursor in the subtropical west Pacific. The event might have also been triggered by SST anomalies in the tropical west Pacific (Hartmann (a) SST on AWT

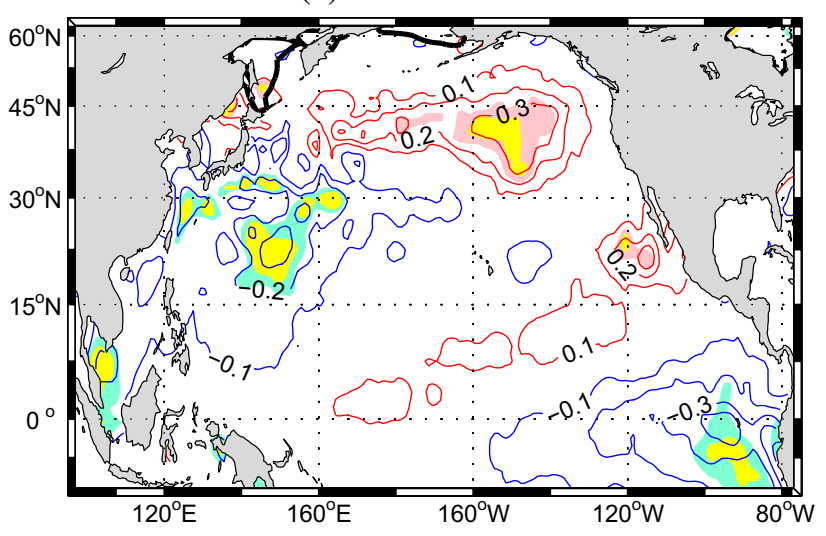

(b) SHF on AWT

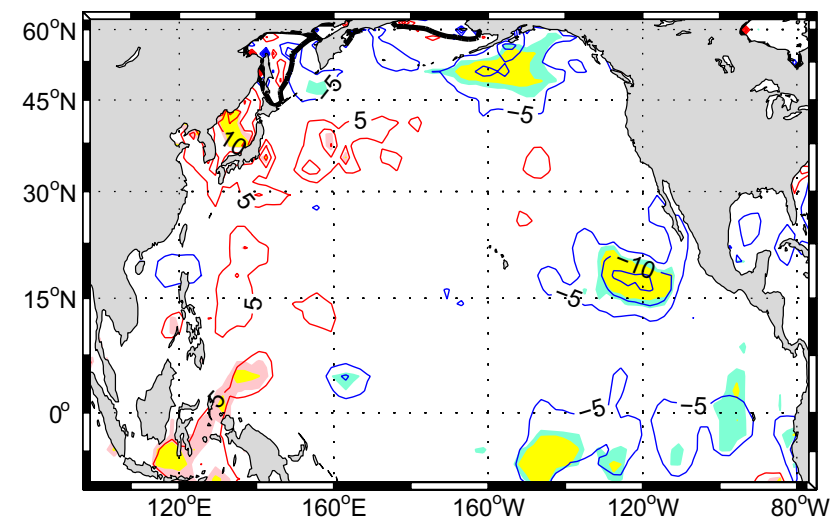

Fig. 12 As Fig. 2 except for winter anomalies of a sea surface temperature and $\mathbf{b}$ surface heat flux (positive upward) in the extratropical North Pacific/tropical Pacific region. In $\mathbf{a}$ and $\mathbf{b}$, the $\mathrm{CI}$ is $0.1 \mathrm{~K}$ and $5 \mathrm{~W} \mathrm{~m}^{-2}$ per unit AWT index, respectively

2015). The possible modulation of such events by forcing from the North Atlantic/Nordic seas sector, which may distort the North Pacific storm track (Fig. 8a), warrants further investigation.

Significant AWT-associated wintertime SST anomalies, albeit weaker than in the North Atlantic, are also found in the North Pacific (Fig. 12a). SST anomalies of the same sign as the AWT anomalies appear in two lobes. The lobe that extends zonally along the North Pacific Current has a significant center of action located under the southern edge of the anomalous atmospheric ridge in the Gulf of Alaska (see Fig. 3). The lobe that extends from the western equatorial Pacific to California is significant in the California Current. These lobes encircle SST anomalies of the opposite sign in the Kuroshio/Kuroshio extension/western North Pacific subtropical gyre region. SST anomalies of the same sign as in this region appear in the eastern tropical Pacific. Higher local correlations with the AWT index are found in the subtropical lobe ( $r$ up to -0.7) than in either 
the tropical lobe ( $r$ up to -0.45 ) or the other two lobes $(r$ up to 0.5 ).

The SST anomaly pattern in Fig. 12a resembles the pattern of SST anomalies regressed onto the principal component time series of the third empirical orthogonal function of deseasoned monthly mean SST for the extratropical North Pacific/tropical Pacific (ocean area $30^{\circ} \mathrm{S}$ $\left.65^{\circ} \mathrm{N}, 120^{\circ} \mathrm{E}-105^{\circ} \mathrm{W}\right)$ over the period $1900-2014$ analyzed by Hartmann (2015, his Fig. 1c) in the context of oceanic forcing of atmospheric anomalies in North America. The subtropical lobe in the west Pacific and the eastern tropical lobe are, however, much stronger in the AWT-associated pattern. Interestingly, the extended SST anomaly patterns associated with all three leading principal component time series for the extratropical North Pacific/tropical Pacific, shown by Hartmann (2015) globally (from $60^{\circ} \mathrm{S}$ to $60^{\circ} \mathrm{N}$ ), lack evident anomalies in the areas of the North Atlantic where significant AWT-associated SST anomalies are observed (Fig. 11a). Moreover, none of them has a strong signal in the subtropical west Pacific where the SST anomalies correlate with the AWT index even higher than the SST anomalies in the Gulf Stream area do. Therefore, the Atlantic-Pacific SST link does not correspond to the major modes of variability in the Pacific. This conclusion does not exclude the possibility that the AWT-associated atmospheric anomalies in the Pacific sector are driven by concurrent local air-sea interaction or that the AWT-associated SST anomalies in this sector are footprints of earlier local air-sea interaction. However, it leaves room for a different scenario, namely, that the AWT-associated changes of the large-scale atmospheric circulation serve as a 'bridge' that transmits oceanic anomalies from the extratropical North Atlantic to the extratropical North Pacific.

The latter scenario can be neither confirmed nor rejected on the basis of the AWT-associated winter surface heat flux anomalies in the North Pacific region (Fig. 12b). In the extratropics, these anomalies generally have the sign suggesting atmospheric forcing of the ocean. In the positive phase of the AWT index, they correspond to cooling of the ocean in the west where cold AWT-associated SST anomalies are observed and to warming of the ocean in the east where warm AWT-associated SST anomalies are observed (Fig. 12a). In addition to the surface thermodynamic forcing, the observed SST anomalies may be generated dynamically via anomalous ocean currents driven by the AWT-associated wind anomalies. A dynamic origin may have, for instance, the warm SST anomaly found under the southern branch of the atmospheric anticyclone that develops over the Gulf of Alaska. Anomalous horizontal advection of mean temperature via the northward Ekman transport driven by the anomalous easterlies (Fig. 3a) should indeed generate a warm SST anomaly in this area. Anomalous Ekman pumping may also contribute to this anomaly. At the same time, a dynamic cooling of the mixed layer may buffer reduction in the oceanic heat loss to the atmosphere observed off Alaska (Fig. 12b). In any case, no evidence is found in the wintertime extratropical fields for substantial oceanic forcing of the atmosphere. In contrast, the anomalous SST lobe in the eastern tropical Pacific coexists with surface heat flux anomalies of the sign consistent with such a forcing. Therefore, the degree to which the AWT-associated atmospheric and oceanic anomalies in the Pacific sector represent a genuine response to oceanic forcing in the North Atlantic/Nordic seas region remains an open question.

\section{Conclusions}

A couple of previous studies investigated climate variability in the Nordic seas region in the period 1982-2006 (Schlichtholz and Houssais 2011; Schlichtholz 2011, 2013, 2014). All of them were based on a regression analysis between observed summertime anomalies of Atlantic water temperature in the Barents Sea opening area (summer AWT index), seasonal mean fields of observed sea surface temperature (and sea ice concentration), and seasonal mean atmospheric fields from the NCEP/NCAR reanalysis. Here we have used the same datasets to explore statistical links between the summer AWT index and atmospheric variability in the Northern Hemisphere extratropics during the following winter. While casual connections between the large-scale atmospheric variability and earlier oceanic heat anomalies cannot be definitely confirmed through regression analysis, our results highlight the relationship.

Our findings can be summarized as follows. Warm summer anomalies of Atlantic water in the Barents Sea opening area are followed by predominantly westerly wind anomalies in high latitudes and easterly wind anomalies in middle latitudes next winter. The mid-latitude wind anomalies, while being generally equivalent barotropic in the upper troposphere, have a strong low-level baroclinic contribution over Eurasia. The near-surface easterly wind anomalies in this region are locally deflected southward, maintaining cold spots near orography. As at the same time a strong warm anomaly is forced over the Barents and Greenland Seas, the lower-tropospheric temperature anomalies exhibit a 'warm Arctic-cold Eurasia' pattern in the positive phase of the AWT index, and conversely, a 'cold Arctic-warm Eurasia' pattern in the negative phase of the AWT index. The 'warm Arctic-cold Eurasia' pattern coexists with a hot spot in an anomalous equivalent-barotropic anticyclone that develops over the Gulf of Alaska.

We have hypothesized that synoptic eddies play a key role in maintaining the AWT-associated remote wind anomalies. In the positive phase of the AWT index, the 
upper-tropospheric storm track activity is enhanced in the Arctic region while it is reduced in middle latitudes, in both the Atlantic and Pacific sector. At low tropospheric levels, the poleward eddy heat flux is increased in the northern part of the Atlantic storm track while it is decreased in its southern part. These relationships may, at least partly, represent a remote atmospheric response to oceanically-driven sea ice anomalies in the Barents and Greenland Seas. Such a scenario is qualitatively consistent with the findings of Inoue et al. (2012) who showed that wintertime atmospheric anomalies over Eurasia are linked to changes in the Barents Sea ice cover via a shift of the storm track in the Nordic seas region. Another mechanism through which oceanic heat variability in this region can affect the large-scale atmospheric circulation may be related to planetary waves. Anomalous planetary waves excited by surface heating in the eastern Arctic have been suggested as a major driver of winter response to, for instance, summer/autumn sea ice anomalies (e.g., Honda et al. 2009; Nakamura et al. 2015). Whether this mechanism plays any role in the AWT-associated wintertime response is currently under investigation.

We have shown that the AWT index represents a coherent system of summertime subsurface ocean heat anomalies in the Nordic seas. These anomalies should reemerge on the surface near the ice edge during the cooling season and then influence the sea ice extent, atmospheric static stability in the marginal ice zone and eddy-mean flow interactions. We have also shown that significant AWT-associated wintertime SST anomalies appear in the entire Nordic seas/ extratropical North Atlantic region. The SST anomalies in the Nordic seas coexist with SST anomalies of the same sign in the Gulf Stream area and SST anomalies of the opposite sign elsewhere. Significant AWT-associated wintertime SST anomalies appear also in the extratropical North Pacific and tropical Pacific. This suggests that some of the relationships reported here may reflect atmospheric response to oceanic anomalies in the North Atlantic or Pacific Ocean. An alternative hypothesis, worth of further investigation, is that the AWT-associated large-scale atmospheric circulation works as a 'bridge' that transmits oceanic anomalies from the extratropical North Atlantic to the extratropical North Pacific.

The correlations compiled in Table 1 show that the relation of wintertime atmospheric variability to the previous summer AWT index is quite strong. This index explains about $40 \%$ of the variance in the near-surface air temperature anomalies over mid-latitude Eurasia $(r=-0.63$ for $T$ at $1000 \mathrm{hPa}$ averaged from $35^{\circ}$ to $45^{\circ} \mathrm{N}$ ) and about $50 \%$ of the variance in the meridional wind anomalies over the Far East Asia $(r=-0.72$ for $v$ at $1000 \mathrm{hPa}$ averaged from $35^{\circ}$ to $45^{\circ} \mathrm{N}$ ). It also explains about $35 \%$ of the variance in the upper-tropospheric zonal wind anomalies over Alaska $(r=0.61$ for $u$ at $300 \mathrm{hPa})$. Moreover, it explains about $60 \%$ of the variance in the upper-tropospheric storm track activity averaged over the mid-latitude Pacific and Eurasia $\left(r=-0.77\right.$ for $\overline{Z^{\prime} Z^{\prime}} 1 / 2$ at $250 \mathrm{hPa}$ averaged from $35^{\circ}$ to $55^{\circ} \mathrm{N}$ ) and about $60 \%$ of the variance in the lowlevel poleward synoptic eddy heat flux averaged over western Eurasia $\left(r=-0.79\right.$ for $\overline{v^{\prime} T^{\prime}}$ at $925 \mathrm{hPa}$ averaged from $45^{\circ}$ to $60^{\circ} \mathrm{N}$ ). The field significance of the AWT-associated anomalies north of $30^{\circ} \mathrm{N}$ exceeds $95 \%$ for all wintertime synoptic covariances analyzed here (Table 3 ).

We have shown that the AWT-associated wintertime atmospheric variability is disconnected from the concurrent North Atlantic Oscillation. If the associations demonstrated in this study are robust, we would expect that inclusion of our AWT index or its equivalent into simple statistical prediction systems (e.g., Folland et al. 2012; Cohen and Jones 2011) should improve their ability to forecast wintertime regional climate variability. Skilful statistical predictions are of practical importance and serve as a benchmark for the more sophisticated dynamical prediction systems (e.g., Smith et al. 2012; Doblas-Reyes et al. 2013; MacLachlan et al. 2014). Links of mid-latitude winter climate anomalies to other promising predictors, such as summer/autumn Arctic sea ice extent or autumn snow cover over Eurasia happen to be nonstationary (e.g., Tang et al. 2013; Li and Wang 2013; Peings et al. 2013). A statistical combination of these predictors with our's may reveal a higher and more robust predictability of the extratropical climate than previously thought.

Prior to constructing a statistical prediction system, we plan to extend our AWT index back in time and forward, beyond 2005, if sufficient number of hydrographic data are available or replace it with an alternative index of subsurface ocean heat variability. Construction of an oceanic predictor of the large-scale wintertime atmospheric variability based on SST anomalies is also envisaged. However, the study on the predictability of the Barents Sea ice cover by Nakanowatari et al. (2014) indicates that the SSTs might not be as useful a predictor as subsurface ocean temperatures.

Acknowledgments This research was supported by the Institute of Oceanology of the Polish Academy of Sciences and the Research Council of Norway through the Polish-Norwegian project PAVE (Atlantic Water Pathways to the Arctic: Variability and Effects on Climate and Ecosystems). The NOAA/OAR/ESRL PSD, Boulder, Colorado, USA, is acknowledged for providing the NCEP Reanalysis Derived data and SST fields from their Web site at http://www.esrl. noaa.gov/psd/. Ocean temperature data were provided by the Oceanographic Database of the International Council for the Exploration of the Sea (http://www.ices.dk/ocean/) and the World Ocean Database (WOD05) of the National Oceanographic Data Center of NOAA (http://www.nodc.noaa.gov/). The NAO index was obtained from the NCAR/UCAR CGD website (http://www.cgd.ucar.edu/cas/jhurrell/). The NINO3.4 index was obtained from the NOAA CPC website (http://www.cpc.ncep.noaa.gov/data/indices/sstoi.indices). The PDO index was obtained from the University of Washington Joint Institute for the Study of the Atmosphere and Ocean website (http://jisao. washington.edu/pdo/PDO.latest). The author thanks two anonymous reviewers and Marie-Noëlle Houssais from LOCEAN, Paris, France, for their helpful comments on the manuscript. 
Open Access This article is distributed under the terms of the Creative Commons Attribution 4.0 International License (http://creativecommons.org/licenses/by/4.0/), which permits unrestricted use, distribution, and reproduction in any medium, provided you give appropriate credit to the original author(s) and the source, provide a link to the Creative Commons license, and indicate if changes were made.

\section{References}

Ådlandsvik B, Loeng H (1991) A study of the climatic system in the Barents Sea. Polar Res 10(1):45-50

Alexander MA, Bladé I, Newman M, Lanzante JR, Lau NC, Scott JD (2002) The atmospheric bridge: the influence of ENSO teleconnections on air-sea interaction over the global oceans. J Clim 15(16):2205-2231

Alexander MA, Bhatt US, Walsh JE, Timlin MS, Miller JS, Scott JD (2004) The atmospheric response to realistic Arctic sea ice anomalies in an AGCM during winter. J Clim 17:890-905

Årthun M, Eldevik T, Smedsrud LH, Skagseth $\varnothing$, Ingvaldsen RB (2012) Quantifying the influence of atlantic heat on Barents Sea ice variability and retreat. J Clim 25:4736-4743

Bengtsson L, Semenov VA, Johannessen OM (2004) The early twentieth-century warming in the Arctic-a possible mechanism. J Clim 17:4045-4057

Beszczynska-Möller A, Fahrbach E, Schauer U, Hansen E (2012) Variability in Atlantic water temperature and transport at the entrance to the Arctic Ocean, 1997-2010. ICES J Mar Sci 69(5):852-863, doi:10.1093/icesjms/fss056

Blackmon ML, Madden RA, Wallace JM, Gutzler DS (1979) Geographical variations in the vertical structure of geopotential height fluctuations. J Atm Sci 36:2450-2466

Boyer TP, Antonov JI, Garcia HE, Johnson DR, Locarnini RA, Mishonov AV, Pitcher MT, Baranova OK, Smolyar IV (2006) World Ocean Database 2005, S. Levitus, Ed., NOAA Atlas NESDIS, vol 60. DVDs, U.S. Govt Print. Off., Washington, D.C

Bretherton CS, Widmann M, Dymnikov VP, Wallace JM, Blade I (1999) The effective number of spatial degrees of freedom of a time-varying field. J Clim 12(7):1990-2009

Cohen J, Screen JA, Furtado JC, Barlow M, Whittleston D, Coumou D, Francis J, Dethloff K, Entekhabi D, Overland J, Jones J (2014) Recent Arctic amplification and extreme mid-latitude weather. Nat. Geosci 7:627-637. doi:10.1038/ngeo2234

Cohen J, Jones J (2011) A new index for more accurate winter predictions. Geophys Res Lett 38(21):L21701. doi:10.1029/201 $1 \mathrm{GL} 049626$

Deser C, Magnusdottir G, Saravanan R, Philips A (2004) The effects of North Atlantic SST and sea ice anomalies on the winter circulation in CCM3. Part II: direct and indirect components of the response. J Clim 17:877-889

Doblas-Reyes FJ, Garca-Serrano J, Lienert F, Biescas AP, Rodrigues LRL (2013) Seasonal climate predictability and forecasting: status and prospects. WIREs Clim Change 4(4):245-268

Folland CK, Scaife AA, Lindesay J, Stephenson DB (2012) How potentially predictable is northern european winter climate a season ahead? Int J Clim 32(6):801-818. doi:10.1002/joc.2314

Francis JA, Chan W, Leathers DJ, Miller JR, Veron DE (2009) Winter Northern Hemisphere weather patterns remember summer Arctic sea-ice extent. Geophys Res Lett 36:L07503. doi:10.1029/2 009GL037274

Frankignoul C, Sennéchael N, Kwon YO, Alexander MA (2011) Influence of the meridional shifts of the Kuroshio and the Oyashio extensions on the atmospheric circulation. J Clim 24(3):762-777
Frankignoul C, Sennéchael N (2007) Observed influence of North Pacific SST anomalies on the atmospheric circulation. J Clim 20:592-606

Hartmann DL (2015) Pacific sea surface temperature and the winter of 2014. Geophys Res Lett 42(6):1894-1902. doi:10.1002/201 5GL063083

Herbaut C, Houssais MN, Close S, Blaizot AC (2015) Two winddriven modes of winter sea ice variability in the Barents Sea. Deep Sea Res Part I 106:97-115. doi:10.1016/j.dsr.2015.10.005

Honda M, Inoue J, Yamane S (2009) Influence of low Arctic sea ice minima on anomalously cold Eurasian winter. Geophys Res Lett 36:L08707. doi:10.1029/2008GL037079

Hopsch S, Cohen J, Dethloff K (2012) Analysis of a link between fall Arctic sea ice concentration and atmospheric patterns in the following winter. Tellus A 64(18):624. doi:10.3402/tellusa. v64i0.18624

Hoskins BJ, Valdes P (1990) On the existence of storm-tracks. J Atm Sci 47:1854-1864

Hurrell JW (1995) Decadal trends in the North Atlantic oscillation: regional temperature and precipitation. Science 269:676-679

Ingvaldsen R, Asplin L, Loeng H (2004) The seasonal cycle in the Atlantic transport to the Barents Sea during the years 19972001. Cont Shelf Res 24:1015-1032

Inoue J, Hori ME, Takaya K (2012) The role of Barents Sea ice in the wintertime cyclone track and emergence of a warm-Arctic coldSiberian anomaly. J Clim 25:2561-2568

International Council for the Exploration of the Sea (2006) Hydrographic Database. http://www.ices.dk/ocean/aspx/hydchem/ hydchem.aspx, Int. Counc. for the Explor. of the Sea, Copenhagen

Jaiser R, Dethloff K, Handorf D, Rinke A, Cohen J (2012) Impact of sea ice cover changes on the Northern Hemisphere atmospheric winter circulation. Tellus A 64(11):595. doi:10.3402/tellusa. v64i0.11595

Kalnay E, Kanamitsu M, Kistler R, Collins W, Deaven D, nad M Iredell LG, Saha S, White G, Woollen J, Zhu Y, Leetmaa A, Reynolds B, nad W Ebisuzaki MC, Higgins W, Janowiak J, Mo KC, Ropelewski C, Wang J, Jenne R, Joseph D (1996) The NCEP/NCAR 40-yr reanalysis project. Bull Amer Meteor Soc $77: 437-471$

Kim BM, Son SW, Min SK, Jeong JH, Kim SJ, Zhang X, Shim T, Yoon JH (2014) Weakening of the stratospheric polar vortex by Arctic sea-ice loss. Nat Com 5:4646. doi:10.1038/ncomms5646

Kushnir Y, Robinson WA, Chang P, Robertson AW (2006) The physical basis for predicting Atlantic sector seasonal-to-interannual climate variability. J Clim 19(23):5949-5970

Livezey RE, Chen WY (1983) Statistical field significance and its determination by Monte Carlo techniques. Mon Wea Rev 111:46-59

Li F, Wang H (2013) Autumn sea ice cover, winter Northern Hemisphere Annular Mode, and winter precipitation in Eurasia. J Clim 26(11):3968-3981

MacLachlan C, Arribas A, Peterson KA, Maidens A, Fereday D, Scaife AA, Gordon M, Vellinga M, Williams A, Comer RE, Camp J, Xavier P, Madec G (2014) Global seasonal forecast system version 5 (glosea5): a high-resolution seasonal forecast system. Q J R Meteorol Soc. doi:10.1002/qj.2396

Mantua N, Hare S, Zhang Y, Wallace J, Francis R (1997) A Pacific interdecadal climate oscillation with impacts on salmon production. Bull Am Meteor Soc 78:1069-1079

Mori M, Watanabe M, Shiogama H, Inoue J, Kimoto M (2014) Robust Arctic sea-ice influence on the frequent Eurasian cold winters in past decades. Nat Geosci 7:869-873. doi:10.1038/ngeo2277

Nakamura T, Yamazaki K, Iwamoto K, Honda M, Miyoshi Y, Ogawa Y, Ukita J (2015) A negative phase shift of the winter AO/NAO due to the recent Arctic sea-ice reduction in late autumn. J Geophys Res Atmos 120(8):3209-3227. doi:10.1002/2014JD022848 
Nakanowatari T, Sato K, Inoue J (2014) Predictability of the Barents Sea ice in early winter: Remote effects of oceanic and atmospheric thermal conditions from the North Atlantic. J Clim 27(23):8884-8901. doi:10.1175/JCLI-D-14-00125.1

Onarheim I, Eldevik T, Årthun M, Ingvaldsen RB, Smedsrud LH (2015) Skillful prediction of Barents Sea ice cover. Geophys Res Lett pp 2015GL064,359+, doi:10.1002/2015g1064359

Orsolini YJ, Senan R, Benestad RE, Melsom A (2013) Impact of snow initialization on sub-seasonal forecasts. Clim Dyn 41:1969-1982

Overland JE, Wang M (2010) Large-scale atmospheric circulation changes are associated with the recent loss of Arctic sea ice. Tellus 62A:1-9

Peings Y, Brun E, Mauvais V, Douville H (2013) How stationary is the relationship between Siberian snow and Arctic Oscillation over the 20th century? Geophys Res Lett 40(1):183-188

Petoukhov V, Semenov VA (2010) A link between reduced BarentsKara sea ice and cold winter extremes over northern continents. J Geophys Res 115:D21111. doi:10.1029/2009JD013568

Polyakov IV, Pnyushkov AV, Timokhov LA (2012) Warming of the intermediate Atlantic water of the Arctic ocean in the 2000s. J Clim 25(23):8362-8370. doi:10.1175/JCLI-D-12-00266.1

Rasmusson EM, Wallace JM (1983) Meteorological aspects of the El-Niño/Southern Oscillation. Science 222(4629):1195-1202. doi:10.1126/science.222.4629.1195

Reynolds RW, Rayner NA, Smith TM, Stokes DC, Wang W (2002) An improved in situ and satellite SST analysis for climate. J Clim 15:1609-1625

Rudels B (2012) Arctic Ocean circulation and variability-advection and external forcing encounter constraints and local processes. Ocean Sci 8:261-286. doi:10.5194/os-8-261-2012

Sato K, Inoue J, Watanabe M (2014) Influence of the Gulf Stream on the Barents Sea ice retreat and Eurasian coldness during early winter. Environ Res Lett 9:084009. doi:10.1088/1748-9326/9/8/084009

Scaife AA, Arribas A, Blockley E, Brookshaw A, Clark RT, Dunstone N, Eade R, Fereday D, Folland CK, Gordon M, Hermanson L, Knight JR, Lea DJ, MacLachlan C, Maidens A, Martin M, Peterson AK, Smith D, Vellinga M, Wallace E, Waters J, Williams A (2014) Skillful long-range prediction of european and north american winters. Geophys Res Lett 41(7):2514-2519. doi:10.1 002/2014GL059637

Schlichtholz P (2011) Influence of oceanic heat variability on sea ice anomalies in the Nordic Seas. Geophys Res Lett 38:L05705. doi: 10.1029/2010GL045894

Schlichtholz P (2013) Observational evidence for oceanic forcing of atmospheric variability in the Nordic seas area. J Clim 26(9):2957-2975. doi:10.1175/JCLI-D-11-00594.1
Schlichtholz P (2014) Local wintertime tropospheric response to oceanic heat anomalies in the Nordic Seas area. J Clim 27(23):8686-8706. doi:10.1175/JCLI-D-13-00763.1

Schlichtholz P, Houssais MN (2002) An overview of the $\theta-S$ correlations in Fram Strait based on the MIZEX 84 data. Oceanologia 44(2):243-272

Schlichtholz P, Houssais MN (2011) Forcing of oceanic heat anomalies by air-sea interactions in the Nordic Seas area. J Geophys Res 116:C01006. doi:10.1029/2009JC005944

Screen JA, Simmonds I (2013) Exploring links between arctic amplification and mid-latitude weather. Geophys Res Lett 40(5):959964. doi:10.1002/grl.50174

Semenov VA, Park W, Latif M (2009) Barents Sea inflow shutdown: a new mechanism for rapid climate changes. Geophys Res Lett 36:L14709. doi:10.1029/2009GL038911

Smedsrud LH, Esau I, Ingvaldsen BR, Eldevik T, Haugan PM et al (2013) The role of the Barents Sea in the Arctic climate system. Rev Geophys 51:415-449. doi:10.1002/rog.20017

Smith DM, Scaife AA, Kirtman BP (2012) What is the current state of scientific knowledge with regard to seasonal and decadal forecasting? Environ Res Lett 37:015602. doi:10.1088/1748-9326/7/1/015602

Takaya K, Nakamura H (2005) Mechanisms of intraseasonal amplification of the cold Siberian High. J Atm Sci 62:4423-4440

Tang Q, Zhang X, Yang X, Francis JA (2013) Cold winter extremes in northern continents linked to Arctic sea ice loss. Environ Res Lett 8(1):014036. doi:10.1088/1748-9326/8/1/014036

Trenberth KE (1986) An assessment of the impact of transient eddies on the zonal flow during a blocking episode using localized Eliassen-Palm flux diagnostics. J Atm Sci 40:2070-2087

Vihma T (2014) Effects of Arctic sea ice decline on weather and climate: a review. Surv Geophys 35:1175-1214. doi:10.1007/ s10712-014-9284-0

von Storch H, Zwiers FW (1999) Statistical analysis in climate research. Cambr. Univ. Press, London

Walczowski W, Piechura J (2007) Pathways of the Greenland Sea warming. Geophys Res Lett 34(10):L10608. doi:10.1029/200 7GL029974

Wang SY, Hipps L, Gillies RR, Yoon JH (2014) Probable causes of the abnormal ridge accompanying the 2013-2014 California drought: ENSO precursor and anthropogenic warming footprint. Geophys Res Lett 41(9):3220-3226. doi:10.1002/2014GL059748

Wu Q, Zhang X (2010) Observed forcing-feedback processes between Northern Hemisphere atmospheric circulation and Arctic sea ice coverage. J Geophys Res 115:D14119. doi:10.1029/2 009JD013574 